\title{
A Model for High-Strain-Rate Deformation of Uranium-Niobium Alloys
}


Los Alamos National Laboratory, an affirmative action/equal opportunity employer, is operated by the University of California for the United States Department of Energy under contract W-7405-ENG-36.

This report was prepared as an account of work sponsored by an agency of the United States Government. Neither the Regents of the University of California, the United States Government nor any agency thereof, nor any of their employees make any warranty, express or implied, or assume any legal liability or responsibility for the accuracy, completeness, or usefulness of any information, apparatus, product, or process disclosed, or represent that its use would not infringe privately owned rights. Reference herein to any specific commercial product, process, or service by trade name, trademark, manufacturer, or otherwise does not necessarily constitute or imply its endorsement, recommendation, or favoring by the Regents of the University of California, the United States Government, or any agency thereof. The views and opinions of authors expressed herein do not necessarily state or reflect those of the Regents of the University of California, the United States Government, or any agency thereof. Los Alamos National Laboratory strongly supports academic freedom and a researcher's right to publish; as an institution, however, the Laboratory does not endorse the viewpoint of a publication or guarantee its technical correctness. 
LA-14034-MS

Issued: May 2003

\title{
A Model for High-Strain-Rate Deformation of Uranium-Niobium Alloys
}

\author{
F.L. Addessio \\ Q.H. Zuo \\ T.A. Mason \\ L.C. Brinson
}

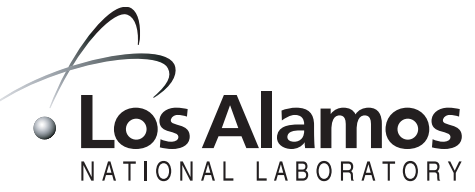





\section{Contents}

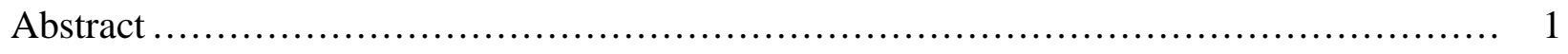

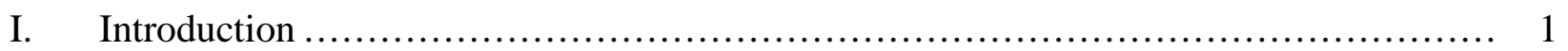

II. Thermodynamic Framework ............................................................ 4

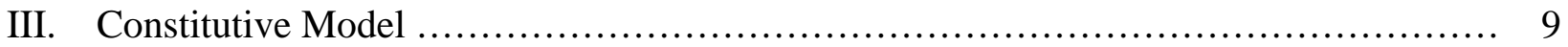

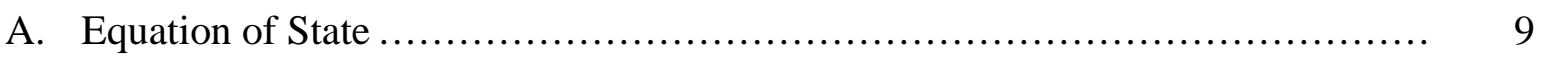

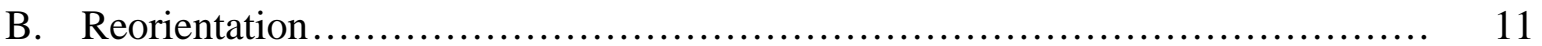

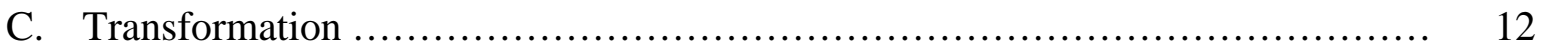

D. Rate-Dependent Plasticity and Ductile Failure …........................... 12

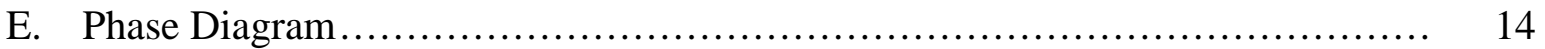

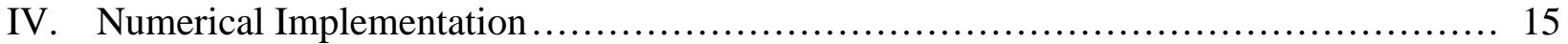

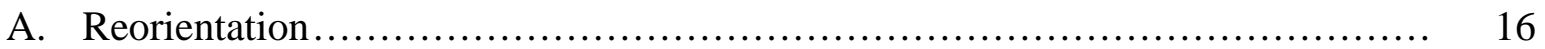

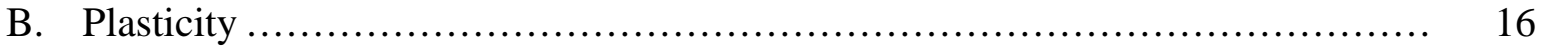

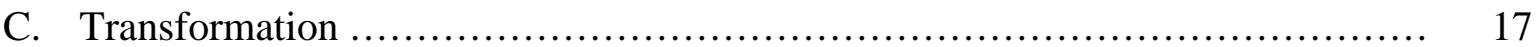

D. Plasticity and Transformation................................................ 18

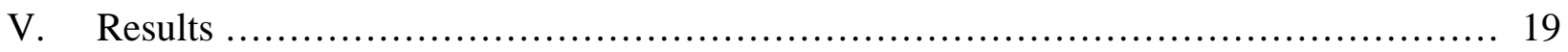

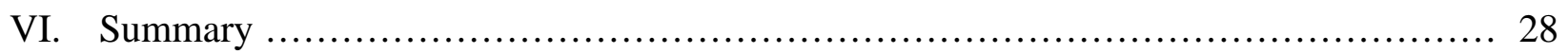

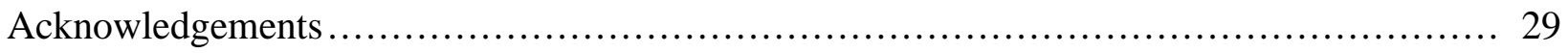

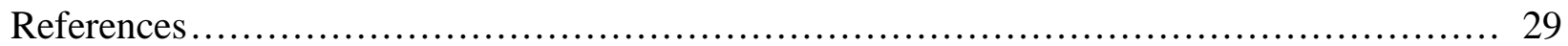

\section{Figures}

Figure 1. Phase diagram for uranium-niobium alloys in the vicinity of the monotectoid [3] .. 2

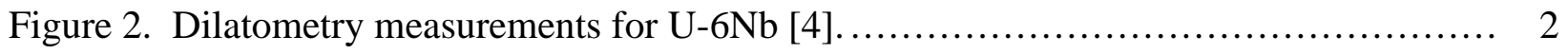

Figure 3. Phase diagram for a representative shape-memory alloy. ........................ 14

Figure 4. Phase diagram used for U-6Nb studies........................................ 15

Figure 5. Representative mechanical response using the material model.................... 22

Figure 6. Comparison of simulations and data [3] for stress and temperature paths versus

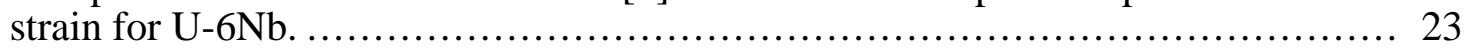

Figure 7. Comparison of simulations and data for uniaxial stress esperiments [5]............. 25

Figure 8. Comparison of simulations and data for plate impact experiments [49]. ............ 26

Figure 9. Schematic diagram of the plate impact experiments [49] ........................ 27

\section{Tables}

Table I. Material parameters (yield strength for the material of Vandermeer [1-4] is provided in parentheses). ..................................................... 20

Table II. Material parameters for crystal reorientation (properties for the material of Vandermeer [1-4] are provided in parentheses).................................. 21

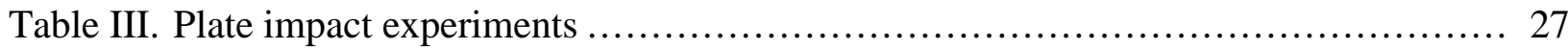


A Model for High-Strain-Rate Deformations of Uranium-Niobium Alloys

\author{
F.L. Addessio*, Q.H. Zuo, T.A. Mason \\ Theoretical Division \\ Los Alamos National Laboratory \\ Los Alamos, NM 87545 \\ (*addessio@lanl.gov) \\ L.C. Brinson
Department of Mechanical Engineering \\ Northwestern University \\ Evanston, IL 60208
}

\begin{abstract}
A thermodynamic approach is used to develop a framework for modeling uraniumniobium alloys under the conditions of high strain rate. Using this framework, a threedimensional phenomenological model, which includes nonlinear elasticity (equation of state), phase transformation, crystal reorientation, rate-dependent plasticity, and porosity growth is presented. An implicit numerical technique is used to solve the evolution equations for the material state. Comparisons are made between the model and data for low-strain-rate loading and unloading as well as for heating and cooling experiments. Comparisons of the model and data also are made for low- and highstrain-rate uniaxial stress and uniaxial strain experiments. A uranium- 6 weight percent niobium alloy is used in the comparisons of model and experiment.
\end{abstract}

\title{
I. Introduction
}

In an effort to improve ductility and corrosion resistance, niobium has been used to alloy uranium. Uranium-niobium (U-Nb) alloys within the range from 5 weight percent $(\mathrm{U}-5 \mathrm{Nb})$ to 8 weight percent $(\mathrm{U}-8 \mathrm{Nb})$ of niobium exhibit the shape memory effect [1-5]. A phase diagram for $\mathrm{U}-\mathrm{Nb}$ alloys in the vicinity of the monotectoid composition $(\mathrm{U}-6 \mathrm{Nb})$ is provided in Fig. 1. At elevated temperatures $(\mathrm{T}>600 \mathrm{~K}), \mathrm{U}-6 \mathrm{Nb}$ is stable in the body-centered cubic (bcc) $\gamma$ phase. As the alloy is cooled rapidly to room temperature, it undergoes a two-stage transformation process. Dilatometry measurements (Fig. 2) indicate that at $\mathrm{T}_{\mathrm{c}} \sim 570 \mathrm{~K}$, a displacement-ordering transformation from the $\gamma$ phase to a distorted bcc (tetragonal) $\gamma^{0}$ phase is observed. The $\gamma$ to $\gamma^{0}$ transformation temperature was denoted $\mathrm{T}_{\mathrm{c}}$ to indicate the constriction arrest, which is the accepted notation for ordering reactions. Because this transformation is a rapid, isothermal transformation at high temperature, an in-situ structural investigation is difficult to obtain. Information can be obtained for this transformation at larger niobium concentrations, where the $\gamma^{0}$ phase exists at room temperature (Fig. 1). This transformation was considered to be a premartensitic phenomenon. As U-6Nb is cooled further, the transformation from the $\gamma^{0}$ phase to the monoclinic $\alpha^{\prime \prime}$ phase is observed. This transformation starts at the temperature $\mathrm{M}_{\mathrm{s}} \sim 435 \mathrm{~K}$ and is finished by $\mathrm{M}_{\mathrm{f}} \sim 350 \mathrm{~K}$. 


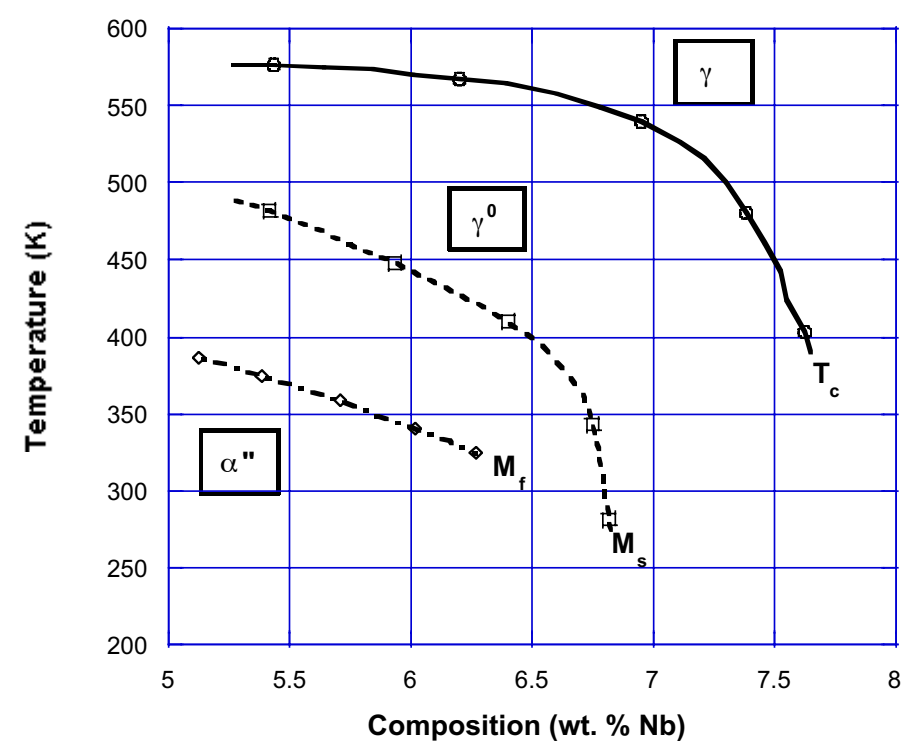

Figure 1. Phase diagram for uranium-niobium alloys in the vicinity of the monotectoid [3].

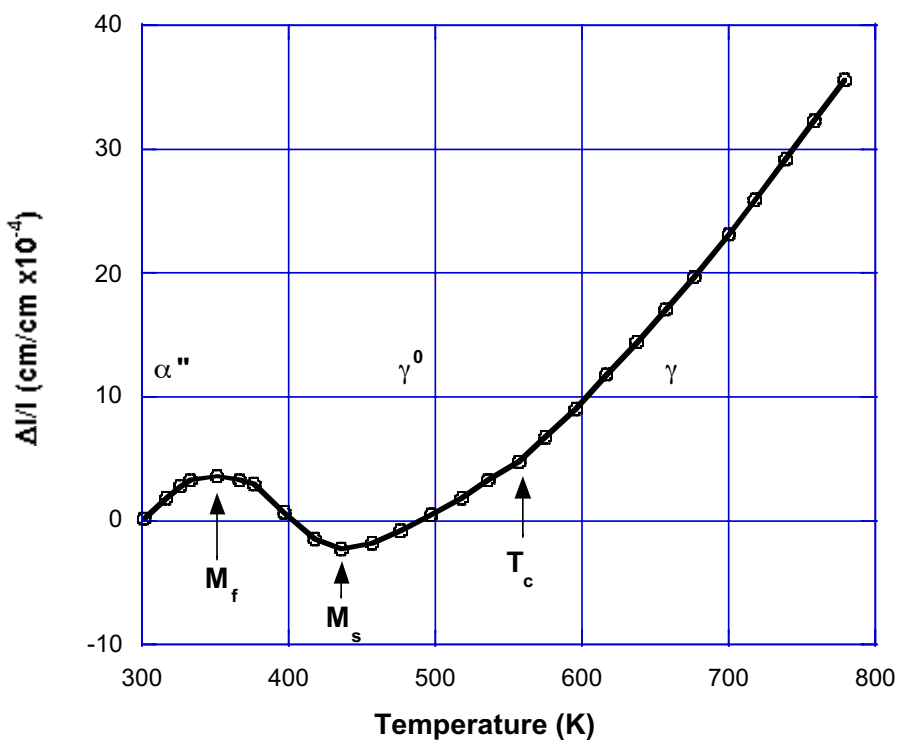

Figure 2. Dilatometry measurements for U-6Nb [4].

The transformations to both $\gamma^{0}$ and $\alpha^{\prime \prime}$ are diffusionless and thought to occur by shear or displacive mechanisms, which require only short-range motions of the atoms. That is, neighboring atoms remain neighbors, but changes in bond angles and lengths result from these transformations. The $\alpha^{\prime \prime}$ phase is metastable and will decompose if the alloy is heated or aged for long periods (years). The aged material exhibits a loss in ductility and corrosion resistance. The $\gamma^{0}$ to $\alpha^{\prime \prime}$ transformation was classified as a martensitic transformation [1-4]: 
1. the $\alpha^{\prime \prime}$ microstructure is similar to nonferrous alloys that undergo a martensitic transformation as determined by diffraction techniques,

2. the volume expansion accompanying the transformation is small,

3. the stress versus strain behavior under uniaxial tension exhibits reorientation of the crystal structure, and

4. the alloy displays strain recovery on heating.

The time for the $\gamma^{0}$ to $\alpha^{\prime \prime}$ transformation is short (approximately $10 \mathrm{~ns}$ ). The martensite start $\left(\mathrm{M}_{\mathrm{s}}\right)$ and finish $\left(\mathrm{M}_{\mathrm{f}}\right)$ temperatures are inverse functions of the heating rate. The dependence of $M_{s}$ and $M_{f}$ on the heating rate decreases for higher rates. The thermal transformation hysteresis associated with the reverse transformation was considered negligible to within experimental error [1,2]. However, recent experiments have better defined the difference between the austenite $\left(\gamma^{0}\right)$ finish $\left(\mathrm{A}_{\mathrm{f}}\right)$ and martensite $\left(\alpha^{\prime \prime}\right)$ start $\left(\mathrm{M}_{\mathrm{s}}\right)$ as well as the austenite start $\left(\mathrm{A}_{\mathrm{s}}\right)$ and martensite finish $\left(\mathrm{M}_{\mathrm{f}}\right)$ temperatures.

At room temperature, the monoclinic $\alpha^{\prime \prime}$ lattice appears as martensite plates, which can form in many orientations (variants) in the same parent phase $(\gamma)$ grains. These variants subdivide the parent grains. The initial crystalline structure is random. Consequently, material texture can be neglected. Furthermore, little difference was observed between the tensile and compressive responses of the material [5]. An elastic material response is observed below strains of approximately $0.3 \%$. As the $\alpha^{\prime \prime}$ phase is loaded beyond strains of $0.3 \%$, the deformation process is dominated by continuous crystalline reorientation associated with a detwinning process, as reported by x-ray and neutron diffraction experiments [6,7]. That is, orientations (variants) that are favored by the loading direction increase in volume fraction at the expense of less favored orientations. This reorientation process is observed for large strains $\left(\varepsilon_{\mathrm{L}} \sim 7 \%\right)$. Once the strain limit $\left(\varepsilon_{\mathrm{L}}\right)$ for the reorientation process is exceeded, dislocation slip is observed to dominate. For strains between $0.3 \%$ and $7 \%$, moderate strain recovery is obtained during a nonlinear unloading process. The yield strength varies little with niobium content for alloys close to the monotectoid composition. Experimental data [5] indicate a minimum yield strength for alloys of 6 weight percent. Heat activated strain recovery $\left(\varepsilon_{R} \sim 4.2 \%\right)$, which is associated with martensite recovery, can be obtained.

Many applications utilizing shape memory alloys (SMAs) require large deformations under high-strain-rate conditions with few mechanical or thermal cycles. Applications include, for example, impact, penetration, and weapons performance scenarios. In addition to phase transitions and reorientation, physical processes including nonlinear elasticity, plastic slip, and failure must be modeled to address large-strain, high-strain-rate deformations. Nonlinear elasticity is necessary to model the material response to shock loading accurately. At high stresses, dislocations are generated within the material, resulting in irreversible strains. Deforming the detwinned state plastically also can inhibit the material from transforming back to the parent state when the temperature of the material is increased. The preferred variant microstructure is 'locked in' by the dislocations, preventing the material from transforming back to the parent or multiple variant microstructure. Subjecting the material to higher stresses ultimately leads to pore nucleation, growth, and coalescence, which result in ductile failure. 
Theories that address the phase transition and reorientation phenomena inherent in SMAs are available for a number of length scales. At the atomistic scale, molecular dynamic simulations have been conducted, which have provided insight into phase transitions [8]. The atomistic models may be used to guide the free-energy formulations used in single-crystal models. On the scale of a single crystal, Ginzburg-Landau [9] and Multi-variant [10-12] theories, which model the phase transition and reorientation processes due to changes in the stress and temperature, are available. Homogenization techniques [13] can be used to obtain the polycrystalline response using the single-crystal theories. The polycrystal theories may be used to develop mechanical potentials, which are necessary for engineering models. Finally, macromechanical models can be implemented into computer analyses to obtain the response of engineering structures utilizing SMAs to mechanical and thermal changes. A number of macromechanical models are available in the literature [14-18]. The majority of the macromechanical models address one-dimensional problems under the conditions of small strains and small strain rates. Models, which address large-strain conditions, including plasticity [19] also have been developed.

A phenomenological approach is provided for modeling high-strain-rate deformations, including nonlinear elasticity, reorientation (twinning), dislocation slip (plasticity), solid-solid phase transitions, and material failure. A framework for the constitutive model will be pursued in Section II, using a thermodynamic approach for modeling SMAs. In Section III, the framework will be generalized to address high-strain-rate applications. An implicit numerical approach for implementing the constitutive model into finite-element or finite-difference structural analyses will be considered in Section IV. Simulations utilizing the model and comparisons to data will be presented in Section V. A summary will be provided in Section VI.

\section{Thermodynamic Framework}

The total specific Helmholtz free energy $\psi(\chi)$, where $\chi=\left[\varepsilon_{i j}^{e}, T, D, \varepsilon^{p}, \varepsilon^{r}, \varepsilon_{i j}^{i}, \xi\right]$ are the state variables, is expressed as the average of the free energy [20-26] of each species $\psi^{k}\left(\varepsilon_{i j}^{e}, T, D, \varepsilon^{p}, \varepsilon^{r}\right), k=M, A$ and the free energy [26] of mixing $\psi^{\text {mix }}\left(\varepsilon_{i j}^{i}, \xi\right)$

$$
\psi(\chi)=\xi \psi^{M}+(1-\xi) \psi^{A}+\psi^{m i x} .
$$

The variables $\varepsilon_{i j}^{e}, \varepsilon_{i j}^{i}$, T, and $\xi$ are the elastic strain, inelastic strain, temperature, and volume fraction of the product phase $(\mathrm{M})$, respectively. Also, $\varepsilon^{p}$ and $\varepsilon^{r}$ are hardening variables for plasticity and crystal reorientation. The variable $\mathrm{D}$ characterizes the amount of material damage. The Helmholtz free energy for the product and parent (A) phases may be written $[20,21,26]$

$$
\begin{gathered}
\psi^{k}\left(\varepsilon_{i j}^{e}, T, D, \varepsilon^{p}, \varepsilon^{r}\right)=\frac{1}{2 \rho}\left[\lambda^{k} \varepsilon_{k k}^{e} \varepsilon_{m m}^{e}+2 \mu^{k} \varepsilon_{i j}^{e} \varepsilon_{i j}^{e}\right]-\frac{1}{\rho} \beta^{k} \varepsilon_{k k}^{e} \theta-\frac{c^{k}}{2 T_{0}} \theta^{2} \\
+\gamma^{k} f^{p}\left(\varepsilon^{p}, D\right)+\eta^{k} f^{r}\left(\varepsilon^{r}\right)-s_{0}^{k} \theta+\psi_{0}^{k} ; k=M, A
\end{gathered} .
$$


It is assumed that the material of interest is isotropic. In Eq. II.2, $\lambda^{k}$ and $\mu^{k}$ are the Lame coefficients, $\beta^{k}=3 \alpha^{k} B^{k}$ where $\alpha^{k}$ is the coefficient of thermal expansion and $B^{k}$ is the bulk modulus ( $\left.B^{k}=\lambda^{k}+\frac{2}{3} \mu^{k}\right), \mathrm{c}^{\mathrm{k}}$ is the specific heat, and $\theta$ is a temperature difference $\left(\theta=T-T_{0}\right.$ ). The reference temperature is $T_{0}$. The parameters $\gamma^{k}$ and $\eta^{k}$ are material parameters related to plasticity and reorientation, respectively. Also, $\rho$ is the material density, which is assumed to be identical for both phases. The function $f^{p}\left(\varepsilon^{p}, D\right)$ is a general isotropic description for plasticity [20]. It is assumed that the material fails in a ductile fashion. Consequently, both strain hardening $\left(\varepsilon^{p}\right)$ and softening due to damage (D) are included in the expression for plasticity [27-29]. The function $f^{r}\left(\varepsilon^{r}\right)$ is an isotropic description for crystal reorientation, which is written in terms of the hardening parameter $\varepsilon^{r}$. The parameters $s_{0}^{k}$ and $\psi_{0}^{k}$ are material constants, which define the reference state. The free energy of mixing is expressed as a quadratic function of the volume fraction of the phases and the inelastic strain [26]

$$
\psi^{m i x}\left(\varepsilon_{i j}^{i}, \xi\right)=\frac{1}{2} b \xi^{2}+\frac{1}{2} b_{i j k l} \varepsilon_{i j}^{i} \varepsilon_{k l}^{i}+b_{i j} \varepsilon_{i j}^{i} \xi
$$

The coefficients $b, b_{i j}$, and $b_{i j k l}$ are material parameters. The rate of deformation (strain rate) is decomposed into its elastic and inelastic components [26]

$$
\dot{\varepsilon}_{i j}=\dot{\varepsilon}_{i j}^{e}+\dot{\varepsilon}_{i j}^{i}
$$

The inelastic rate of deformation $\left(\dot{\varepsilon}_{i j}^{i}\right)$ includes the rates due to crystal reorientation $\left(\dot{\varepsilon}_{i j}^{r}\right)$, phase transformation $\left(\dot{\varepsilon}_{i j}^{t}\right)$, and slip plasticity $\left(\dot{\varepsilon}_{i j}^{p}\right)$. Furthermore, it is assumed that the rate of deformation due to transformation may be expressed as [26, 30-33]

$$
\dot{\varepsilon}_{i j}^{t}=\Lambda_{i j} \dot{\xi}
$$

where [26]

$$
\Lambda_{i j}=\left\{\begin{array}{c}
\frac{3}{2} h_{0} \frac{s_{i j}}{\tau}+\frac{1}{3} g_{0} \delta_{i j}: \dot{\xi} \geq 0 \\
h_{0} \frac{e_{i j}^{t}}{e^{t}}+\frac{1}{3} g_{0} \delta_{i j}: \dot{\xi}<0
\end{array}\right\} .
$$

In Eq. II.6, $s_{i j}$ is the deviatoric component of the stress $\left(s_{i j}=\sigma_{i j}-\frac{1}{3} \sigma_{k k} \delta_{i j}\right), \tau$ is the von Mises stress $\left(\tau=\sqrt{\frac{3}{2} S_{i j} S_{i j}}\right)$, and $e^{t}$ is the effective transformation strain $\left(\dot{e}^{t}=\sqrt{\frac{2}{3} \dot{e}_{i j}^{t} \dot{e}_{i j}^{t}}\right)$. The deviatoric component of strain is $e_{i j}$. Also, $h_{0}$ and $g_{0}$ are material constants, where $h_{0}$ is the recovery strain and $g_{0}$ is the relative volume change due to transformation. 
The generalized thermodynamic forces may be derived using Eqs. II.1-II.3 [20-22]

$$
\begin{aligned}
s= & -\frac{\partial \psi}{\partial T}=\frac{\beta}{\rho} \varepsilon_{k k}^{e}+\frac{c}{T_{0}} \theta+s_{0} \\
\sigma_{i j}= & \rho \frac{\partial \psi}{\partial \varepsilon_{i j}^{e}}=\lambda \varepsilon_{k k}^{e} \delta_{i j}+2 \mu \varepsilon_{i j}^{e}-\beta \theta \delta_{i j} \\
\Omega^{d}= & \rho \frac{\partial \psi}{\partial D}=\rho \gamma \frac{\partial f^{p}\left(\varepsilon^{p}, D\right)}{\partial D} \\
\Omega^{p}= & \rho \frac{\partial \psi}{\partial \varepsilon^{p}}=\rho \gamma \frac{\partial f^{p}\left(\varepsilon^{p}, D\right)}{\partial \varepsilon^{p}} \\
\Omega^{r}= & \rho \frac{\partial \psi}{\partial \varepsilon^{r}}=\rho \eta \frac{\partial f^{r}\left(\varepsilon^{r}\right)}{\partial \varepsilon^{r}} \\
\mu_{i j}^{i}= & \rho \frac{\partial \psi}{\partial \varepsilon_{i j}^{i}}=\rho\left(b_{i j k l} \varepsilon_{k l}^{i}+b_{i j} \xi\right) \\
\mu^{\xi}= & \rho \frac{\partial \psi}{\partial \xi} \\
= & \frac{1}{2}\left(\Delta \lambda \varepsilon_{k k}^{e} \varepsilon_{m m}^{e}+2 \Delta \mu \varepsilon_{i j}^{e} \varepsilon_{i j}^{e}\right)-\Delta \beta \varepsilon_{k k}^{e} \theta-\frac{\rho \Delta c}{2 T_{0}} \theta^{2} \\
& +\rho\left[\Delta \gamma f^{p}\left(\varepsilon^{p}, D\right)+\Delta \eta f^{r}\left(\varepsilon^{r}\right)-\Delta s_{0} \theta+\Delta \psi_{0}+b \xi+b_{i j} \varepsilon_{i j}^{i}\right]
\end{aligned} .
$$

In Eq II.7, $\mathrm{s}$ and $\sigma_{i j}$ are the entropy and Cauchy stress, respectively. Average material properties $\left(\lambda, \mu, \beta, c, s_{0}, \gamma, \eta\right)$ are defined using the rule of mixtures, e.g.

$$
\lambda=\xi \lambda^{M}+(1-\xi) \lambda^{A} .
$$

Also, $\Delta \lambda=\lambda^{M}-\lambda^{A}$ denotes the difference in the material properties of the product and parent phases.

Consider the Clausius-Duhem inequality [20-23], which defines the dissipation rate $\left(\Phi_{\mathrm{d}}\right)$ for the thermomechanical process in the absence of external heat sources

$$
\Phi_{d}=\sigma_{i j} \dot{\varepsilon}_{i j}-\rho(\dot{\psi}+s \dot{T})-\frac{q_{i} T_{, i}}{T} \geq 0,
$$

where $q_{i}$ is the heat flux. Substituting Eqs. II.4, II.5, and II.7 into Eq. II.9 results in the expression for the dissipation rate

$$
\Phi_{d}=\left(\Sigma_{i j} \dot{\varepsilon}_{i j}^{r}-\Omega^{r} \dot{\varepsilon}^{r}\right)+\Pi \dot{\xi}+\left(\Sigma_{i j} \dot{\varepsilon}_{i j}^{p}-\Omega^{d} \dot{D}-\Omega^{p} \dot{\varepsilon}^{p}\right)-\frac{q_{i} T_{, i}}{T} \geq 0 .
$$

The thermodynamic variables $\Sigma_{\mathrm{ij}}$ and $\Pi$ are defined as [26] 


$$
\begin{aligned}
& \Sigma_{i j}=\sigma_{i j}-\mu_{i j}^{i} \\
& \Pi=\Sigma_{i j} \Lambda_{i j}-\mu^{\xi}
\end{aligned}
$$

It is assumed that the dissipation may be decomposed [20] into four separate and independent processes, three mechanical (reorientation, phase transformation, and combined slip plasticity and damage) and one thermal. Therefore, three independent mechanical potentials for reorientation, transformation, and plasticity $\left(\phi^{r}, \phi^{t}\right.$, and $\left.\phi^{p}\right)$ will be defined, from which the inelastic parameters may be obtained $[20,21,24]$

$$
\begin{aligned}
& \dot{\varepsilon}_{i j}^{r}=\frac{\partial \phi^{r}\left(\sum_{i j}, \Omega^{r}\right)}{\partial \Sigma_{i j}} \dot{\lambda}^{r} \\
& \dot{\varepsilon}^{r}=-\frac{\partial \phi^{r}\left(\Sigma_{i j}, \Omega^{r}\right)}{\partial \Omega^{r}} \dot{\lambda}^{r} \\
& \dot{\xi}=\frac{\partial \phi^{t}(\Pi)}{\partial \Pi} \dot{\lambda}^{t} \\
& \dot{\varepsilon}_{i j}^{p}=\frac{\partial \phi^{p}\left(\Sigma_{i j}, \Omega^{d}, \Omega^{p}\right)}{\partial \Sigma_{i j}} \dot{\lambda}^{p} \\
& \dot{\varepsilon}^{p}=-\frac{\partial \phi^{p}\left(\Sigma_{i j}, \Omega^{d}, \Omega^{p}\right)}{\partial \Omega^{p}} \dot{\lambda}^{p} \\
& \dot{D}=-\frac{\partial \phi^{p}\left(\Sigma_{i j}, \Omega^{d}, \Omega^{p}\right)}{\partial \Omega^{d}} \dot{\lambda}^{p}
\end{aligned}
$$

In Eqs. II.12, $\dot{\lambda}^{r}, \dot{\lambda}^{t}$, and $\dot{\lambda}^{p}$ are the Lagrange multipliers for crystal reorientation, transformation, and plasticity, respectively. The thermal potential results in Fourier's Law for heat conduction [20]. Consider, for example, the inelastic mechanical potentials

$$
\begin{aligned}
& \phi^{r}=\sqrt{\frac{3}{2} \Sigma_{i j}^{\prime} \Sigma_{i j}^{\prime}}-\left[\Omega^{r}\left(\varepsilon^{r}\right)+\Omega_{0}^{r}\right]=0 \\
& \phi^{t}=\Pi \mp Y^{t}=0 \\
& \phi^{p}=\sqrt{\frac{3}{2} \Sigma_{i j}^{\prime} \Sigma_{i j}^{\prime}}-Y^{p}\left(\Omega^{d}, \Omega^{p}, \Sigma\right)=0
\end{aligned}
$$

In Eq. II.13, $\Sigma_{i j}^{\prime}=\Sigma_{i j}+\Sigma \delta_{i j}$ and $\Sigma=-\frac{1}{3} \Sigma_{k k}$ are the deviatoric and volumetric components of $\Sigma_{i j}$, respectively. The two signs (+/-) in Eq. II.13b allow for hysteresis [26] in the phase transformation process. The inelastic variables may be obtained from Eqs. II.12 and II.13. Therefore, for crystal reorientation and transformation, the inelastic variables are

$$
\begin{aligned}
& \dot{\varepsilon}_{i j}^{r}=\frac{3 \Sigma_{i j}^{\prime}}{2 \Sigma^{\prime}} \dot{\lambda}^{r} \\
& \dot{\varepsilon}^{r}=\dot{\lambda}^{r} \\
& \dot{\xi}=\dot{\lambda}^{t}
\end{aligned}
$$


The multipliers for reorientation $\left(\dot{\lambda}^{r}\right)$ and transformation $\left(\dot{\lambda}^{t}\right)$ are obtained from the consistency conditions $\left(\dot{\phi}^{r}=0\right.$ and $\left.\dot{\phi}^{t}=0\right)$. In Eq. II.14, $\Sigma^{\prime}$ is an effective stress $\left(\Sigma^{\prime}=\sqrt{\frac{3}{2} \sum_{i j}^{\prime} \Sigma_{i j}^{\prime}}\right)$.

Assume, for example, that the plastic term in the expression for the Helmholtz free energy (Eq. II.2) may be written

$$
f^{p}\left(\varepsilon^{p}, D\right)=\frac{\Sigma_{0}}{\rho} g\left(\varepsilon^{p}\right) \ln (1-D) .
$$

Also, if the plastic-yield function degrades linearly with the hydrostatic stress $(\Sigma<0)$ and linearly with damage, then

$$
Y^{p}\left(\Omega^{d}, \Omega^{p}, \Sigma\right)=(1-D) h(\Sigma)\left[\Omega^{p}-\Omega_{0}^{p}\right]=-\frac{\gamma \Sigma_{0} g\left(\varepsilon^{p}\right) h(\Sigma)}{\Omega^{d}}\left(\Omega^{p}-\Omega_{0}^{p}\right)
$$

Substituting Eqs. II.15 and II.16 into II.12 provides the plastic-strain rate $\left(\dot{\varepsilon}_{i j}^{p}\right)$, the strain-ratehardening variable $\left(\dot{\varepsilon}^{p}\right)$, and the rate of change of damage $(\dot{D})$ :

$$
\begin{aligned}
& \dot{\varepsilon}_{i j}^{p}=\left(\frac{3 \Sigma_{i j}^{\prime}}{2 \Sigma^{\prime}}+\frac{1}{3} \frac{\partial Y^{p}}{\partial \Sigma} \delta_{i j}\right) \dot{\lambda}^{p} \\
& \dot{\varepsilon}^{p}=(1-D) h(\Sigma) \dot{\lambda}^{p} \\
& \dot{D}=(1-D) \frac{h(\Sigma)}{\gamma \Sigma_{0} g\left(\varepsilon^{p}\right) h^{\prime}(\Sigma)} \dot{\varepsilon}_{k k}^{p}
\end{aligned}
$$

Eq. II.17c resembles a classical void growth expression [27] if the damage (D) is interpreted as the void volume fraction $(\phi)$. The advantage of this associative formulation is that the ClausiusDuhem inequality is satisfied automatically. That is, with a judicious choice for the inelastic mechanical potentials in terms of the generalized thermodynamic forces, an associated formulation can be obtained systematically for the state variables $\left(\varepsilon_{i j}^{r}, \varepsilon^{r}, \xi, \varepsilon_{i j}^{p}, \varepsilon^{p}, D\right)$, which automatically satisfy the dissipation inequality. 


\section{Constitutive Model}

In an effort to address high-strain-rate applications, the framework developed in Section II will be generalized in a heuristic fashion. Extensions include nonlinear elasticity (equation of state), rate-dependent plasticity, and ductile failure by porosity growth. Phenomenological mechanical potentials for crystal reorientation, phase transformation, and plasticity will be introduced for demonstrative purposes. Physically based potentials will be pursued in a future investigation. Finally, a phase diagram will be introduced as a method of summarizing the model in a two-dimensional (stress versus temperature) space.

\section{A. Equation of State}

From Eq. II.7b, the stress is written as

$$
\sigma_{i j}=\lambda \varepsilon_{k k}^{e} \delta_{i j}+2 \mu \varepsilon_{i j}^{e}-\beta \theta \delta_{i j}
$$

The expression for the stress (Eq. III.1) will be generalized in this section to include highpressure effects. The stress $\left(\sigma_{i j}\right)$ is decomposed into its deviatoric $\left(s_{i j}\right)$ and volumetric $\left(P=-\frac{1}{3} \sigma_{k k}\right)$ components

$\sigma_{i j}=s_{i j}-P \delta_{i j}$

The deviatoric component is written directly from Eq. III.1

$$
s_{i j}=2 \mu e_{i j}^{e}
$$

For most metals, it is a good assumption to include the effects of nonlinear elasticity only in the volumetric (pressure) component. A nonlinear expression for the pressure is referred to as the equation of state. Consider a porous material composed of the solid material and voids. Neglecting the gas pressure in the voids, the equation of state for this porous material may be written as [29]

$$
P(\phi, v, e, \xi)=(1-\phi) P_{s}\left(v_{s}, e_{s}, \xi\right) .
$$

In Eq. III.4, $\phi$ is the porosity or void volume fraction. The solid material properties are subscripted (i.e., $v_{s}, e_{s}, P_{s}$ ). Also, $v$ and $e$ are the specific volume and the specific internal energy of the porous material, respectively. The difference between the solid $\left(e_{s}\right)$ and porous material

(e) internal energies is related to the void surface energy, which is small [29]. Therefore, it will be assumed that $e \sim e_{\mathrm{s}}$. The equation of state for the solid material may be written, for example [34],

$$
P_{s}\left(\varepsilon_{s}, e_{s}, \xi\right)=P_{H}\left(1+\frac{1}{2} \Gamma_{s} \varepsilon_{s}\right)+\rho_{s 0} \Gamma_{s}\left(1-\varepsilon_{s}\right) e_{s}
$$


In Eq. III.5, $\Gamma_{\mathrm{s}}$ is the Gruneisen coefficient of the solid material and $\rho_{s 0}$ is a reference density. The density is written in terms of the volumetric strain $\left(\varepsilon_{s}=1-\rho_{s} / \rho_{s 0}\right)$. The Hugoniot pressure may be approximated by a polynomial,

$$
P_{H}=a_{1} \varepsilon_{s}+a_{2}\left(\varepsilon_{s}\right)^{2}+a_{3}\left(\varepsilon_{s}\right)^{3}
$$

The material coefficients in Eqs. III.5 and III.6 are obtained using a rule of mixtures (Eq. II.8) to account for the differences in the two phases. Using Eqs. III.2 through III.4, the stress field may be updated from the incremental expressions

$$
\begin{aligned}
& d s_{i j}+r_{i j} d t=2 \mu d e_{i j}^{e}+\frac{\Delta \mu}{\mu} s_{i j} d \xi \\
& d P=(1-\phi)\left\{\frac{\partial P_{s}}{\partial v_{s}} d v_{s}+\frac{\partial P_{s}}{\partial e_{s}} d e_{s}+\frac{\partial P_{s}}{\partial \xi} d \xi\right\}-P_{s} d \phi
\end{aligned}
$$

In Eq III.7a, the term $r_{i j}$ accounts for material rotation $[35,36]$. For example, if a Jaumann-Noll stress rate is used, then

$$
r_{i j}=s_{i k} \omega_{k j}-\omega_{i k} s_{k j}
$$

where $\omega_{i j}$ is the spin tensor. An alternative approach would be to solve the constitutive model in the unrotated reference frame [37]. Eq. III.7b may be written as

$$
d P=-B d \varepsilon_{k k}+\Gamma_{s} s_{i j} d e_{i j}+\alpha d \varepsilon_{k k}^{p}+K d \xi
$$

where $\alpha=B-\left(1+\Gamma_{s}\right) P$. Eq. III.9 is obtained using the equations for conservation of mass,

$$
\frac{d v}{v}=d \varepsilon_{k k}
$$

and conservation of energy, in the absence of heat flux and heat source terms,

$$
d e=v \sigma_{i j} d \varepsilon_{i j} .
$$

Also, the growth of damage or porosity (Eq. II.17c) is expressed in terms of the volumetric plastic strain [27]

$$
d \phi=(1-\phi) d \varepsilon_{k k}^{p}
$$

The bulk modulus $\left(B_{s}\right)$, the Gruneisen coefficient $\left(\Gamma_{s}\right)$, and the transformation coefficient $\left(K_{s}\right)$ for the solid constituent are defined by the thermodynamic derivatives 


$$
\begin{aligned}
& B_{s}=-v_{s}\left(\frac{\partial P_{s}}{\partial v_{s}}\right)_{s}=P_{s} \Gamma_{s}-v_{s}\left(\frac{\partial P_{s}}{\partial v_{s}}\right)_{e_{s}} \\
& \Gamma_{s}=v_{s}\left(\frac{\partial P_{s}}{\partial e_{s}}\right)_{v_{s}} \\
& K_{s}=\frac{\partial P_{s}}{\partial \xi} \approx \frac{\Delta B_{s}}{B_{s}} P_{s}
\end{aligned}
$$

It is assumed that the bulk material properties are degraded linearly with solidity (i.e., $B=\omega B_{s}$ where $\omega=1-\phi)$. Therefore, once an equation of state has been defined for the material, the bulk modulus, Gruneisen coefficient, and transformation coefficient may be derived using Eqs. III.13. In the above development, it has been assumed that the damage (D) is equivalent to the porosity $(\phi)$.

\section{B. Reorientation}

Consider the irreversible potential for reorientation provided by Eq. II.13,

$$
\phi^{r}\left(\Sigma_{i j}, \Omega^{r}\right)=\sqrt{\frac{3}{2} s_{i j} s_{i j}}-\left[\Omega^{r}\left(\varepsilon^{r}\right)+\Omega_{0}^{r}\right]=0
$$

where the back-stress $\left(\mu_{\mathrm{ij}}^{\mathrm{i}}\right)$ has been neglected (Eq. II.11a). From Eqs. II.12 and III.14, expressions for the rate of deformation $\left(\dot{\varepsilon}_{i j}^{r}\right)$ and rate of hardening $\left(\dot{\varepsilon}^{r}\right)$ due to reorientation, may be obtained as

$$
\begin{aligned}
& \dot{\varepsilon}_{i j}^{r}=\frac{\partial \phi^{r}}{\partial \sigma_{i j}} \dot{\lambda}^{r}=\frac{3 s_{i j}}{2 \tau} \dot{\lambda}^{r} \\
& \dot{\varepsilon}^{r}=-\frac{\partial \phi^{r}}{\partial \Omega^{r}} \dot{\lambda}^{r}=\dot{\lambda}^{r}
\end{aligned} .
$$

The parameter $\dot{\lambda}^{r}$ may be obtained from the consistency condition $\left(\dot{\phi}^{r}=0\right)$

$$
\dot{\lambda}^{r}=\frac{3 \mu}{\tau} S_{i j} \dot{e}_{i j}\left(3 \mu+\frac{d \Omega^{r}}{d \varepsilon^{r}}\right)^{-1} .
$$

Eqs. III.15 and III.16 provide the expression for the reorientation strain rate and hardening once the function $\Omega^{r}$ has been specified. 


\section{Transformation}

Neglecting hysteresis, the transformation potential may be written (Eq. II.13)

$$
\phi^{t}=\Pi=0 \text {. }
$$

The thermodynamic force $\Pi$ (Eq. II.11) is approximated as

$$
\Pi \approx h_{0} \tau-g_{0} P-\rho b \xi+\rho \Delta s_{0} \theta-\rho \Delta \psi_{0} .
$$

This approximation for $\Pi$ results in linear transformation boundaries in the $\tau-\mathrm{T}$ and P-T planes, which are used in classical approaches for shape-memory alloys. The rate of change of the martensite volume fraction may be written (Eq. II.12)

$$
\dot{\xi}=\frac{\partial \phi^{t}}{\partial \Pi} \dot{\lambda}^{t}=\dot{\lambda}^{t}
$$

Again the parameter $\dot{\lambda}^{t}$ may be obtained from the consistency condition $\left(\dot{\phi}^{t}=0\right)$

$$
\dot{\xi}=\frac{1}{\rho b}\left[h_{0} \dot{\tau}-g_{0} \dot{P}+\rho \Delta s_{0} \dot{T}+\rho\left(b \xi-\Delta s_{0} \theta+\Delta \psi_{0}\right) \dot{\varepsilon}_{k k}\right] .
$$

The material constants are obtained in a $\tau$-T plane as

$$
\begin{aligned}
\Delta s_{0} & =-\frac{h_{0}}{\rho} \frac{\Delta \tau}{\Delta T} \\
b & =\Delta s_{0}\left(M_{F}-M_{s}\right) . \\
\Delta \psi_{0} & =\Delta s_{0}\left(M_{s}-T_{0}\right)
\end{aligned}
$$

In Eq. III.21, the martensitic start $\left(\mathrm{M}_{\mathrm{s}}\right)$ and finish $\left(\mathrm{M}_{\mathrm{f}}\right)$ temperatures are the temperatures that define the beginning and end of the phase transition from the parent (A) to the product (M) phases for zero stress conditions. The slope of the transformation boundary $\left(c_{m} \equiv \Delta \tau / \Delta T\right)$ is assumed constant.

\section{Rate-Dependent Plasticity and Ductile Failure}

The mechanical potential for plasticity, including material hardening and softening, is expressed as [27-29]

$$
\phi^{p}=\frac{\frac{3}{2} s_{i j} s_{i j}}{\left[Y_{s}^{p}\left(\varepsilon_{s}^{p}, \dot{\varepsilon}_{s}^{p}, T\right)\right]^{2}}-Y^{\phi}(\phi, p)=0 .
$$

There are numerous models for the plastic flow stress $\left(Y_{s}^{p}\right)$. For this development, a phenomenological model will be used [38] 


$$
Y_{s}^{p}\left(\varepsilon_{s}^{p}, \dot{\varepsilon}_{s}^{p}, T\right)=\left[c_{1}+c_{2}\left(\varepsilon_{s}^{p}\right)^{n}\right]\left[1+c_{3} \ln \left(\frac{\dot{\varepsilon}_{s}^{p}}{\dot{\varepsilon}_{0}}\right)\right]\left[1-\left(\frac{T-T_{0}}{T_{m}-T_{0}}\right)^{m}\right]
$$

In Eq. III.23, $T_{m}$ is the melting temperature of the material, and $\dot{\varepsilon}_{0}=1 \mathrm{~s}^{-1}$ is a reference strain rate. The constants $c_{i}, n$, and $m$ are material parameters. Also, $\dot{\varepsilon}_{s}^{p}$ is the equivalent plastic-strain rate in the solid material. The equivalent plastic-strain rate for the solid may be obtained from an expression for the balance of plastic work [27]

$$
\frac{Y_{s}^{p} \dot{\varepsilon}_{s}^{p}}{\rho_{s}}=\frac{\sigma_{i j} \dot{\varepsilon}_{i j}^{p}}{\rho}
$$

In Eq. (III.24), $\rho / \rho_{s}=1-\phi$. [27-29]

The degradation of the strength of the material as a result of porosity growth is written as

$$
Y^{\phi}(\phi, P)=1+(q \phi)^{2}-2 q \phi \cosh \left(-\frac{3 P}{2 Y_{0}}\right)
$$

In Eq. III.25, $q$ and $Y_{0}$ are material constants. Referring to Eq. II.12, the plastic-strain rate may be written

$$
\dot{\varepsilon}_{i j}^{p}=\left(\frac{3 s_{i j}}{2 \tau}-\frac{1}{3} \frac{\partial \phi^{p}}{\partial P} \delta_{i j}\right) \dot{\lambda}^{p}
$$

The growth of porosity (Eq. II.17c) is approximated as [27]

$$
\phi \approx(1-\phi) \dot{\varepsilon}_{k k}^{p}
$$

The right-hand side of the equation for the rate of change of porosity includes only the effect of void growth. A more general expression also should include void nucleation and coalescence [27]. These effects will be included in a future effort. 


\section{E. Phase Diagram}

A phase diagram $[14,15]$ provides a convenient method for representing the constitutive model that was developed in the previous sections. The phase diagram is defined in equivalent stress $(\tau)$ and temperature $(\mathrm{T})$ space. A phase diagram, which has been used in numerous models for shape-memory alloys, is shown in Fig. 3. For this phase diagram, crystal reorientation of the martensitic (product) phase occurs between the critical start $\left(\tau_{s}^{r}\right)$ and finish $\left(\tau_{f}^{r}\right)$ stresses. Also, plastic slip is defined by the yield stress $\left(\tau^{p}\right)$. In Fig. 3, the transformation from the austenitic (parent) phase to the martensitic phase begins at the boundary defined by the stress $\tau^{s}=\tau_{M S}(T)$ and ends at the boundary $\tau^{f}=\tau_{M F}(T)$. The reverse transformation (martensite to austenite) begins and ends at the boundaries $\tau_{A S}(T)$ and $\tau_{A F}(T)$, respectively. In Fig. 3, the directions of the phase transformations are indicated by the arrows. This phase diagram includes hysteresis in the transformation process.

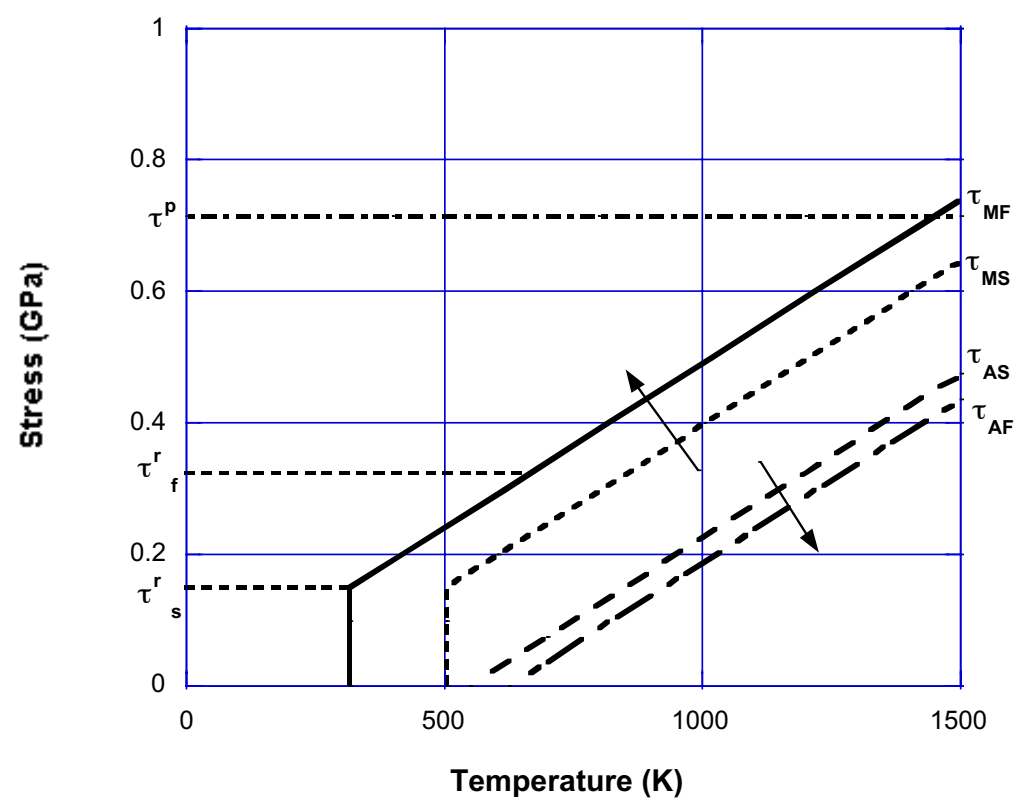

Figure 3. Phase diagram for a representative shape-memory alloy.

The deformation of uranium-niobium (U-Nb) alloys is considered in this investigation. The proposed $\tau-\mathrm{T}$ phase diagram for $\mathrm{U}-\mathrm{Nb}$ is shown in Fig. 4. This phase diagram was constructed using information that is available for $\mathrm{U}-\mathrm{Nb}$ alloys [1-5]. Negligible transformation hysteresis has been observed for U-Nb [1-4]. Therefore, only one region $\left(\phi^{t}=0\right)$ is used to define both the forward and the reverse transformations. Also, only the $\gamma^{0}$ and $\alpha^{\prime \prime}$ phases are considered in this investigation. The $\gamma$ phase will be included in future investigations, as the necessary information related to the transformation process and the material properties for the high-temperature phase become available. The phase transformation region is defined by the linear boundaries $\tau^{s}(T)$ and $\tau^{f}(T)$. Crystal reorientation, which is defined by the potential $\phi^{r}$, is initiated at the stress $\tau^{r}=\Omega^{r}+\Omega_{0}^{r}$. Based on experimental observations [6,7], it was determined that reorientation of the low-temperature phase $\left(\alpha^{\prime \prime}\right)$ is initiated at a critical stress $\left(\tau^{r}\right)$ and continues until dislocation slip is observed. This approach differs from previous methods [16,17] where it was concluded that an elastic region exists between the reorientation and dislocation slip regimes with the elastic moduli of the twinned and detwinned states being 
different. Although reorientation and plasticity occur simultaneously, they will be modeled as separate processes in this model. Therefore, the reorientation process is assumed to end at the start of crystal slip, which is defined by $\tau^{p}=Y_{s}^{p} \sqrt{Y^{\phi}}$. This assumption is justified by the experimental observation that below $7 \%$ strain, most of the strain may be recovered by heating.

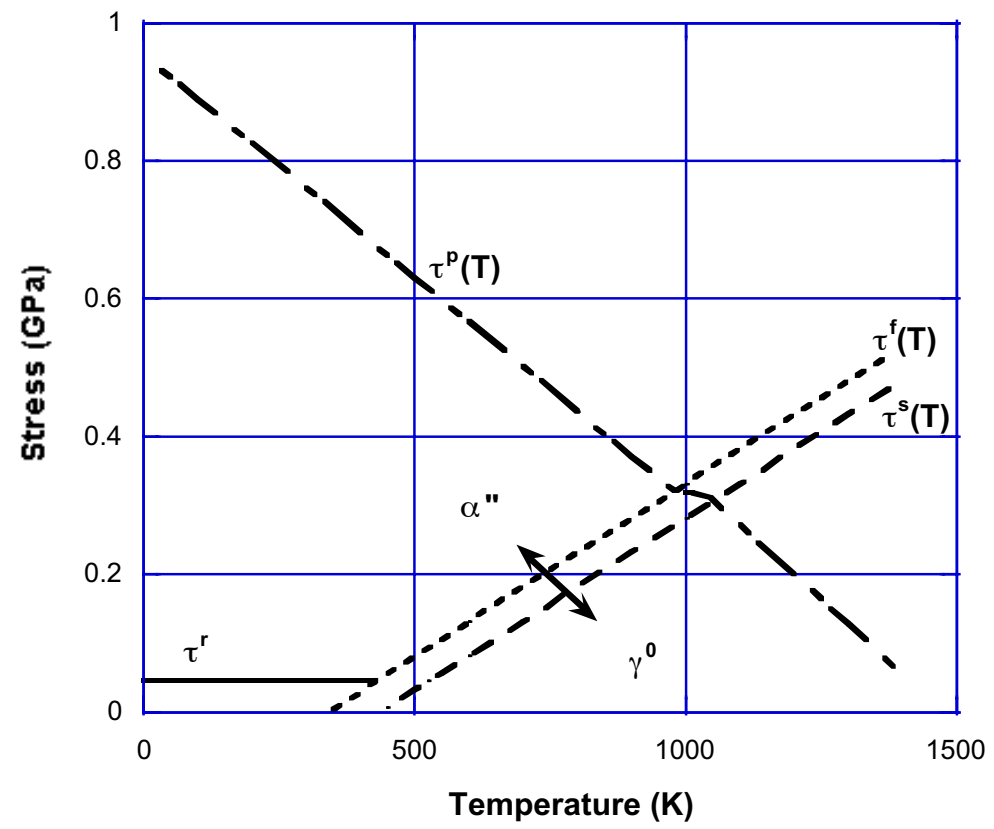

Figure 4. Phase diagram used for U-6Nb studies.

\section{Numerical Implementation}

For a dynamic analysis, the material state may be obtained knowing the rate of deformation $\left(\dot{\varepsilon}_{i j}\right)$ and the temperature (T) fields, which result from solutions to the conservation of momentum and energy equations, respectively. A robust and numerically efficient implicit numerical algorithm [39,40] has been used to implement the proposed model. An implicit approach offers the advantage of placing no additional stability constraints on the time-step size $(\delta t)$ of the dynamic analysis, which utilizes the constitutive model. Consequently, compared to an explicit algorithm, larger time-step sizes may be used and hence a significant reduction in the cost of the analysis can be achieved. In this development, $\tau^{\mathrm{s}}$ is the stress defining the start ( $\xi=0$ ) of the phase transformation region and $\tau^{\mathrm{f}}$ is the stress defining the end $(\xi=1)$ of the phase transformation region for a specified temperature (T). The values of $\tau^{s}$ and $\tau^{f}$ are obtained from the transformation potential $\left(\phi^{t}\right)$. Also, the plastic stress is defined as $\tau^{p}=Y_{s}^{p} \sqrt{Y^{\phi}}$. Similarly, the reorientation stress is $\tau^{r}=\Omega^{r}+\Omega_{0}^{r}$ (Fig. 4). 
For each computational cell, a trial-material state $\left[\mathrm{s}^{*}{ }_{\mathrm{ij}}, \mathrm{P}^{*}, \phi^{*}, \xi^{*}\right]$ is computed first, assuming a purely elastic deformation

$$
\begin{aligned}
& s_{i j}^{*}=s_{i j}^{n}+\left(2 \mu \dot{e}_{i j}-r_{i j}\right) \delta t \\
& P^{*}=P^{n}-\left(B \dot{\varepsilon}_{k k}-\Gamma_{s} s_{i j} \dot{e}_{i j}\right) \delta t \\
& \phi^{*}=\phi^{n} \\
& \xi^{*}=\xi^{n}
\end{aligned}
$$

where $s_{i j}^{n}, P^{n}, \phi^{n}$, and $\xi^{n}$ are the values of the material state at the end of the previous time step. The trial-material state obtained from Eqs. IV.1 is used to determine where the material state lies on the phase diagram (Fig. 4).

\section{A. Reorientation}

If the trial-stress state satisfies the conditions $\tau^{\mathrm{r}}<\tau^{*}<\tau^{\mathrm{p}}$ and $\tau^{*}>\tau^{\mathrm{f}}$, then the new material state is obtained utilizing the system of equations that apply for crystal reorientation

$$
\begin{aligned}
& s_{i j}=s_{i j} *-2 \mu \delta e_{i j}^{r} \\
& P=P^{*} \\
& \delta \varepsilon_{i j}^{r}=\frac{3 s_{i j}}{2 \tau} \delta \lambda^{r}, \\
& \tau=\Omega^{r}\left(\varepsilon^{r}\right)+\Omega_{0}^{r}
\end{aligned}
$$

where $\delta \lambda^{r}=\delta \varepsilon^{r}$. Also, $\delta \lambda^{r}$ is the incremental change in the variable $\lambda^{r}$ for the time step (i.e., $\left.\delta \lambda^{r}=\dot{\lambda}^{r} \delta t\right)$. Eqs. IV.2 are used to develop the following equations for the new material state $\left(s_{i j}, P, \varepsilon_{i j}^{r}, \varepsilon^{r}\right)$

$$
\begin{aligned}
& {\left[1+\frac{3 \mu}{\tau} \delta \lambda^{r}\right] \tau=\tau^{*},} \\
& \tau-\Omega^{r}\left(\lambda^{r}\right)=\Omega_{0}^{r}
\end{aligned}
$$

where $\tau^{*}=\sqrt{\frac{3}{2} S_{i j} * s_{i j} *}$. Eliminating $\tau$, Eq. IV.3 provides a simple nonlinear equation for the reorientation strain. The remaining variables may be obtained by a back-substitution procedure.

\section{B. Plasticity}

If the trial state satisfies the conditions $\tau^{*}>\tau^{\mathrm{p}}$ and $\tau^{*}<\tau^{\mathrm{s}}$ or $\tau^{\mathrm{f}}<\tau^{*}$, then the new material state is determined by the equations that define plastic deformation, including porosity growth 


$$
\begin{aligned}
& s_{i j}=s_{i j} *-2 \mu \delta e_{i j}^{p} \\
& P=P^{*}+\alpha \delta \varepsilon_{k k}^{p} \\
& \phi=\phi^{*}+(1-\phi) \delta \varepsilon_{k k}^{p} \\
& \delta \varepsilon_{i j}^{p}=\left(\frac{\partial \phi^{p}}{\partial s_{i j}}-\frac{1}{3} \frac{\partial \phi^{p}}{\partial P} \delta_{i j}\right) \delta \lambda^{p} \\
& \phi^{p}=\left(\frac{\tau}{Y_{s}^{p}}\right)^{2}-Y^{\phi}(\phi, P)
\end{aligned}
$$

A solution for Eqs. IV.4 can be obtained by solving a system of nonlinear equations for the material state $\left(\tau, P, \phi, \delta \lambda^{p}\right)$

$$
\begin{aligned}
& \left(1+\frac{6 \mu}{\left(Y_{s}^{p}\right)^{2}} \delta \lambda^{p}\right) \tau=\tau^{*} \\
& P-\alpha \frac{\partial Y^{\phi}}{\partial P} \delta \lambda^{p}=P^{*} \\
& \phi-(1-\phi) \frac{\partial Y^{\phi}}{\partial P} \delta \lambda^{p}=\phi^{*} \\
& \tau^{2}-\left(Y_{s}^{p}\right)^{2} Y^{\phi}=0
\end{aligned}
$$

In deriving Eqs. IV.5, the following expressions for the incremental plastic strains were used:

$$
\begin{aligned}
& \delta e_{i j}^{p}=\frac{3 s_{i j}}{\left(Y_{s}^{p}\right)^{2}} \delta \lambda^{p} \\
& \delta \varepsilon_{k k}^{p}=\frac{3 q \phi}{Y_{0}} \sinh \left(\frac{-3 P}{2 Y_{0}}\right) \delta \lambda^{p}
\end{aligned}
$$

In the numerical strategy, a solution of Eqs. IV.5 is obtained by eliminating the von Mises stress $(\tau)$. Next, an iterative solution for the pressure $(P)$ and plastic multiplier $\left(\delta \lambda^{p}\right)$ is obtained, holding the porosity $(\phi)$ fixed. The remaining state variables are obtained using a backsubstitution process.

\section{Transformation}

If the trial state satisfies the conditions $\tau^{\mathrm{s}}<\tau^{*}<\tau^{\mathrm{f}}$ and $\tau^{*}<\tau^{\mathrm{p}}$, then the new material state is determined by the equations that define phase transformation 


$$
\begin{aligned}
& s_{i j}=s_{i j} *-2 \mu \delta e_{i j}^{t}+\frac{\Delta \mu}{\mu} s_{i j} \delta \xi \\
& P=P^{*}+\frac{\Delta B}{B} P \delta \xi \\
& \delta \varepsilon_{i j}^{t}=\left(\frac{3}{2} h_{0} \frac{s_{i j}}{\tau}+\frac{1}{3} g_{0} \delta_{i j}\right) \delta \xi \\
& \phi^{t}=h_{0} \tau-g_{0} P-\rho b \xi+\rho \Delta s_{0} \theta-\rho \Delta \psi_{0}=0
\end{aligned}
$$

Eqs. (IV.7) may be used to develop a system of nonlinear equations for the stress state $[\tau, \mathrm{P}, \xi]$

$$
\begin{aligned}
& {\left[1+\left(\frac{3 \mu h_{0}}{\tau}-\frac{\Delta \mu}{\mu}\right) \delta \xi\right] \tau=\tau^{*}} \\
& \left(1-\frac{\Delta B}{B} \delta \xi\right) P=P^{*} \\
& h_{0} \tau-g_{0} P-\rho b \xi=\rho\left(\Delta \psi_{0}-\Delta s_{0} \theta\right)
\end{aligned}
$$

By eliminating the von Mises stress $(\tau)$, a simple iterative technique is used to solve for the pressure $(P)$ and martensite volume fraction $(\xi)$. The remaining state variables are obtained by back substitution.

\section{Plasticity and Transformation}

If the trial state satisfies the conditions $\tau^{\mathrm{s}}<\tau^{*}<\tau^{\mathrm{f}}$ and $\tau^{*}>\tau^{\mathrm{p}}$, then the new stress state is determined by the equations that define combined phase transformation and plasticity, including porosity growth,

$$
\begin{aligned}
& s_{i j}=s_{i j}{ }^{*}-2 \mu\left(\delta e_{i j}^{p}+\delta e_{i j}^{t}\right)+\frac{\Delta \mu}{\mu} s_{i j} \delta \xi \\
& P=P^{*}+\alpha \delta \varepsilon_{k k}^{p}+\frac{\Delta B}{B} P \delta \xi \\
& \phi=\phi^{*}+(1-\phi) \delta \varepsilon_{k k}^{p} \\
& \delta \varepsilon_{i j}^{p}=\left(\frac{\partial \phi^{p}}{\partial s_{i j}}-\frac{1}{3} \frac{\partial \phi^{p}}{\partial P} \delta_{i j}\right) \delta \lambda^{p} \\
& \delta \varepsilon_{i j}^{t}=\left(\frac{3}{2} h_{0} \frac{s_{i j}}{\tau}+\frac{1}{3} g_{0} \delta_{i j}\right) \delta \xi \\
& \phi^{p}=\left(\frac{\tau}{Y_{s}^{p}}\right)^{2}-Y^{\phi}(\phi, P)=0 \\
& \phi^{t}=h_{0} \tau-g_{0} P+\rho\left(\Delta s_{0} \theta-b \xi-\Delta \psi_{0}\right)=0
\end{aligned}
$$

Eqs. IV.9 may be used to develop a system of nonlinear equations for the material state $\left[\tau, P, \phi, \delta \lambda^{p}, \delta \xi\right]$ 


$$
\begin{aligned}
& {\left[1+\frac{6 \mu}{\left(Y_{s}^{p}\right)^{2}} \delta \lambda^{p}+\left(\frac{3 \mu h_{0}}{\tau}-\frac{\Delta \mu}{\mu}\right) \delta \xi\right] \tau=\tau^{*}} \\
& \left(1-\frac{\Delta B}{B} \delta \xi\right) P-\alpha \frac{\partial Y^{\phi}}{\partial P} \delta \lambda^{p}=P^{*} \\
& \phi-(1-\phi) \delta \varepsilon_{k k}^{p}=\phi^{*} \\
& \left(\frac{\tau}{Y_{s}^{p}}\right)^{2}-Y^{\phi}=0 \\
& h_{0} \tau-g_{0} P-\rho b \xi=\rho\left(\Delta \psi_{0}-\Delta s_{0} \theta\right)
\end{aligned}
$$

The plastic strains $\left(\delta \varepsilon_{i j}^{p}\right)$ and transformation strains $\left(\delta \varepsilon_{i j}^{t}\right)$ are obtained from Eqs. IV.6 and IV.7, respectively. Again, the von Mises stress $(\tau)$ is eliminated from Eqs. IV.10. A new material state is obtained by iteratively solving for the pressure $(P)$, martensite volume fraction $(\xi)$, and the plastic multiplier $\left(\delta \lambda^{p}\right)$, while holding the porosity $(\phi)$ fixed. The remaining state variables are obtained by back substitution.

\section{Results}

The model developed in the previous sections is used to simulate both high- and lowstrain-rate deformations of $\mathrm{U}-6 \mathrm{Nb}$, including the effects of phase transformations, crystal reorientation, plasticity, and failure. A limited number of properties for $\mathrm{U}-6 \mathrm{Nb}$ are available in the literature [1-5,41-46]. Unfortunately, the available properties vary significantly with the pedigree of the material (i.e., heat treatment, forming process, impurities, grain size, etc.). It also is difficult to obtain all of the necessary material parameters, especially the properties for the high-temperature phases $\left(\gamma\right.$ and $\left.\gamma^{0}\right)$ and those necessary to define the phase diagram. Consequently, only the $\gamma^{0}$ and $\alpha^{\prime \prime}$ phases are modeled in the simulations provided. The $\gamma$ phase will be included when the data necessary to define the material properties are available. Two material pedigrees are considered in this investigation. The material used in the experiments of Cady, et al. [5] was chosen as the baseline material. The material properties are provided in Table I. With the exception of the yield strength, the properties for the $\gamma^{0}$ phase were taken to be identical to the $\alpha^{\prime \prime}$ phase. The yield strength $\left(\mathrm{c}_{1}\right)$ for the $\alpha^{\prime \prime}$ and $\gamma^{0}$ phases were taken to be 0.780 and $0.875 \mathrm{GPa}$, respectively. These values were based on data for U-6Nb and U-8Nb [5]. The material used by Vandermeer, et al. [1-4] was chosen as the second pedigree. Only the initial yield strength was modified $\left(c_{1}=0.640 \mathrm{GPa}\right)$ relative to the baseline parameters in Table I for the second material. The phase transformation start $\left(\mathrm{M}_{\mathrm{s}}\right)$ and finish $\left(\mathrm{M}_{\mathrm{f}}\right)$ temperatures were

obtained from Vandermeer, et al. [1-4]. Additional data are being pursued to define better the necessary material properties. The values of the bulk modulus $\left(\mathrm{B}_{\mathrm{s}}\right)$ and the Gruneisen coefficient $\left(\Gamma_{\mathrm{s}}\right)$ are assumed constant for the simulations. 
Table I. Material parameters (yield strength for the material of Vandermeer [1-4] is provided in parentheses).

\begin{tabular}{|l|c|c|}
\hline Material Parameter & U-Nb $[\mathbf{1 - 5}$ and 41-46] & Quartz [50-53] \\
\hline$\rho\left(\mathrm{gm} / \mathrm{cm}^{3}\right)$ & 17.42 & 2.65 \\
\hline$\mu(\mathrm{GPa})$ & 28.0 & 10.0 \\
\hline $\mathrm{B}(\mathrm{GPa})$ & 114.0 & 95.4 \\
\hline$\Gamma$ & 2.03 & 0.653 \\
\hline $\mathrm{c}(\mathrm{cal} / \mathrm{gm} \mathrm{K})$ & 0.0275 & 0.1863 \\
\hline $\mathrm{T}_{\text {melt }}(\mathrm{K})$ & 1475 & 270 \\
\hline $\mathrm{T}_{0}(\mathrm{~K})$ & 270 & \\
\hline $\mathrm{c}_{\mathrm{m}}(\mathrm{GPa} / \mathrm{K})$ & 0.0005 & \\
\hline $\mathrm{q}$ & 1.0 & \\
\hline$\phi_{0}$ & 0.001 & \\
\hline $\mathrm{Y}_{0}(\mathrm{GPa})$ & 0.55 & \\
\hline$\gamma_{0}$ & -0.34 & \\
\hline$\gamma_{\mathrm{d}}$ & 2.50 & \\
\hline$\gamma_{\mathrm{a}}$ & -0.50 & \\
\hline$\phi_{\mathrm{f}}$ & 0.30 & \\
\hline $\mathrm{c}_{1}(\mathrm{GPa})$ & & \\
\hline $\mathrm{c}_{2}(\mathrm{GPa})$ & $0.780(0.640) / 0.875$ & \\
\hline $\mathrm{c}_{3}$ & 0.253 & \\
\hline $\mathrm{n}$ & 0.0118 & \\
\hline $\mathrm{m}$ & 0.220 & \\
\hline & 1.0 & \\
\hline $\mathrm{h}_{0}$ & & \\
\hline $\mathrm{g}_{0}$ & 0.09 & \\
\hline & 0.0 & \\
\hline $\mathrm{M}_{\mathrm{s}}(\mathrm{K})$ & 430 & \\
\hline $\mathrm{M}_{\mathrm{f}}(\mathrm{K})$ & 340 & \\
& & \\
\hline
\end{tabular}

Crystal reorientation is modeled for the $\alpha^{\prime \prime}$ phase only. A piecewise linear function was used to model the inelastic potential $\left(\phi^{r}\right)$ for crystal reorientation. That is, the functional form for the reorientation flow stress is

$$
\begin{gathered}
\Omega^{r}\left(\varepsilon^{r}\right)=\Omega_{k}(\dot{\varepsilon})+m_{k}(\dot{\varepsilon})\left[\varepsilon^{r}-\varepsilon_{k}(\dot{\varepsilon})\right], \quad k=1,2,3 \\
\Omega_{k}(\dot{\varepsilon})=a_{Y k}+b_{Y k}\left(\dot{\varepsilon}-0.1 s^{-1}\right) \\
m_{k}(\dot{\varepsilon})=a_{m k}+b_{m k}\left(\dot{\varepsilon}-0.1 s^{-1}\right) \\
\varepsilon_{k}(\dot{\varepsilon})=a_{\varepsilon k}+b_{\varepsilon k}\left(\dot{\varepsilon}-0.1 s^{-1}\right)
\end{gathered}
$$


Values for the parameters $\left(a_{Y k}, b_{Y k}, a_{m k}, b_{m k}, a_{\varepsilon k}\right.$, and $\left.b_{\varepsilon k}\right)$ in Eq. V.1 are provided in Table II for both the materials of Cady and Vandermeer (in parentheses). Only quasi-static experiments were available for the Vandermeer material. Consequently, the strain-rate effect was not modeled for this material ( $b_{Y k}=b_{m k}=b_{\varepsilon k}=0$ ). These parameters were chosen to provide a good comparison to the uniaxial stress experiments.

Table II. Material parameters for crystal reorientation (properties for the material of Vandermeer [1-4] are provided in parentheses).

\begin{tabular}{|l|l|l|l|}
\hline $\mathbf{k}=$ & $\mathbf{1}$ & $\mathbf{2}$ & $\mathbf{3}$ \\
\hline$a_{Y k}(\mathrm{GPa})$ & $0.04453(0.04200)$ & $0.23004(0.15800)$ & $0.40451(0.25200)$ \\
\hline$b_{Y k}(\mathrm{GPa} \mathrm{s})$ & $1.170 \times 10^{-4}(0.0)$ & $0.827 \times 10^{-4}(0.0)$ & $0.354 \times 10^{-4}(0.0)$ \\
\hline$a_{m k}(\mathrm{GPa})$ & $35.47(26.40)$ & $6.61(5.60)$ & $16.29(0.0)$ \\
\hline$b_{m k}(\mathrm{GPa} \mathrm{s})$ & $-6.59 \times 10^{-3}(0.0)$ & $-7.83 \times 10^{-4}(0.0)$ & $1.10 \times 10^{-5}(0.0)$ \\
\hline$a_{\varepsilon k}$ & $0.00033(0.00030)$ & $0.0056(0.0047)$ & $0.0319(0.0214)$ \\
\hline$b_{\varepsilon k}(\mathrm{~s})$ & $3.85 \times 10^{-7}(0.0)$ & $3.95 \times 10^{-7}(0.0)$ & $-4.90 \times 10^{-6}(0.0)$ \\
\hline
\end{tabular}

Void nucleation has not been modeled in the existing theory. Void nucleation may be included by the addition of a term $\left(\dot{\phi}_{n}\right)$ to Eq. III.27 [27]. Void coalescence may be included by accelerating the rate of production of porosity after a critical value $\left(\phi_{f}\right)$ is achieved [27]. In the existing approach, however, the stiffness of a computational cell is set to zero when the stress state reaches a surface defined in stress-triaxiality $(P / \tau)$, plastic strain $\left(e^{p}\right)$, and porosity $(\phi)$ space $[29,38]$

$$
\begin{aligned}
& \left(\frac{\phi}{\phi_{f}}\right)^{2}+\left(\frac{e^{p}}{e_{f}^{p}}\right)^{2}=1 \\
& e_{f}^{p}=\gamma_{0}+\gamma_{d} \exp \left(-\gamma_{a} P / \tau\right)
\end{aligned}
$$

Values for the constants in Eq. V.2 also are provided in Table I [41].

A representative stress-versus-strain path using the proposed model is provided in Fig. 5 . The conditions of uniaxial stress and a constant temperature $(750 \mathrm{~K})$, which is higher than the martensitic start temperature $\left(\mathrm{M}_{\mathrm{s}}=430 \mathrm{~K}\right)$, are imposed for this simulation. The material initially is in the austenitic $\left(\gamma^{0}\right)$ phase. An elastic response $\left(\varepsilon^{e}\right)$ is followed up to a stress of approximately $0.16 \mathrm{GPa}$. Between approximately $0.16 \mathrm{GPa}$ and $0.20 \mathrm{GPa}$ the deformation path is within the phase transformation regime $\left(\varepsilon^{t}\right)$, where the material is converted from austenite $\left(\gamma^{0}\right)$ to martensite $\left(\alpha^{\prime \prime}\right)$. Crystal reorientation $\left(\varepsilon^{r}\right)$ follows between $0.20 \mathrm{GPa}$ and approximately 0.57 $\mathrm{GPa}$. The remaining part of the loading path is within the plastic regime $\left(\varepsilon^{\mathrm{p}}\right)$ up to a strain of 0.20 . The unloading path initially follows a linear elastic path $\left(\varepsilon^{\mathrm{e}}\right)$ followed by the transformation from martensite to austenite $\left(\varepsilon^{t}\right)$ and finally, linear elastic unloading to a state of zero stress. A residual strain of approximately 0.125 is realized for this representative deformation. 


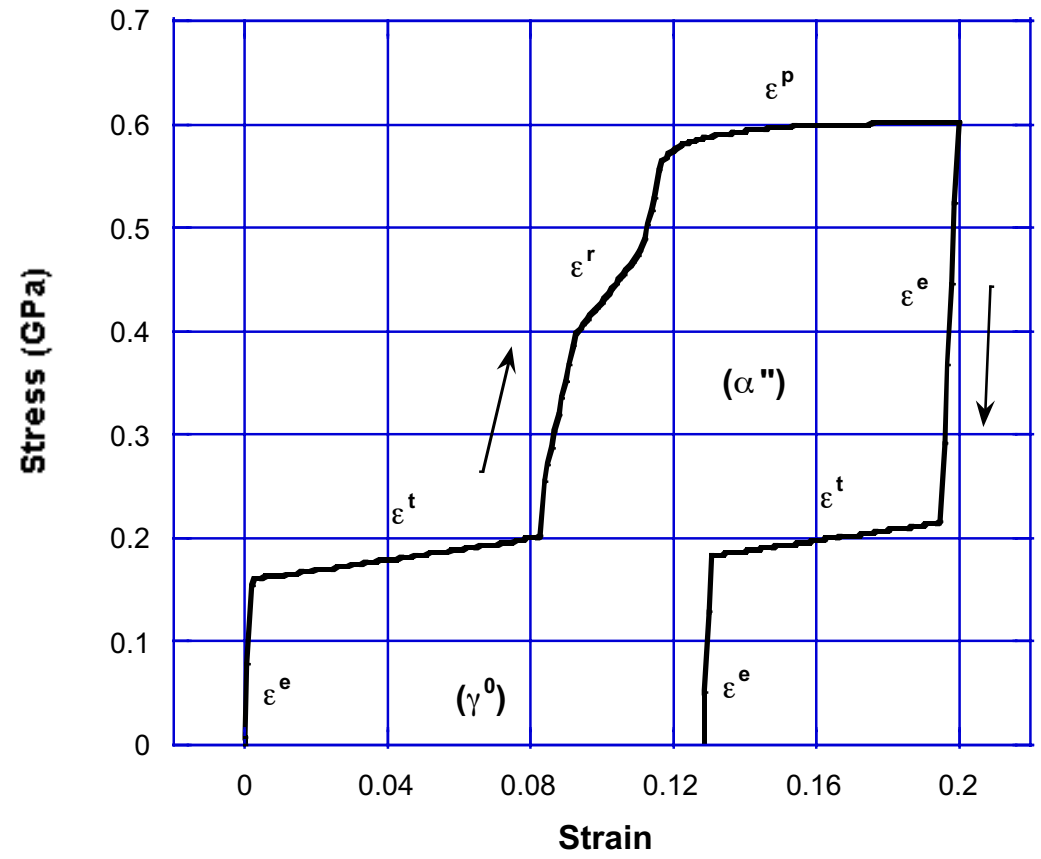

Figure 5. Representative mechanical response using the material model.

Consider the experimentally observed thermomechanical cycles [3] shown in Fig. 6. The self-accommodated (multiple variant or twinned) $\alpha^{\prime \prime}$ phase is loaded in tension at room temperature (Fig. 6a). The elastic limit is reached at a strain of approximately $0.3 \%$, where the reorientation process is initiated. At a strain of approximately 7\%, dislocation slip begins. After a strain of $7 \%$ is reached, the load is removed. A nonlinear unloading path is observed. Then the strained specimen is heated to a temperature of $1100 \mathrm{~K}\left(\mathrm{~T}_{\max }\right)$ and cooled to room temperature (Fig. 6b). The 5\% strain, which remains after unloading, is recovered in two stages during this thermal process. The initial 3\% strain is recovered during the heating process, when the $\alpha^{\prime \prime}$ phase transforms back to the $\gamma$ phase. Most of the heat-activated shape recovery is observed during the heating process for the temperature range of $350 \mathrm{~K}<\mathrm{T}<435 \mathrm{~K}$, where the $\alpha^{\prime \prime}$ to $\gamma^{0}$ reversion occurs. Depending on the maximum amount of strain applied to the specimen, between $90 \%$ to $100 \%$ of the heat-activated recovery process occurs between room temperature and 500 $\mathrm{K}$. This deformation and heating process is analogous to the shape memory effect. The remaining $2 \%$ recovery in strain is obtained during the cooling process. Above $7 \%$ strain (Fig. 6a), irreversible deformations (dislocation slip) are observed. A loading path to $17 \%$ strain followed by unloading, heating, and cooling also is provided in Fig. 6b. The irreversible deformation may be observed for the $17 \%$ strain experiment. 


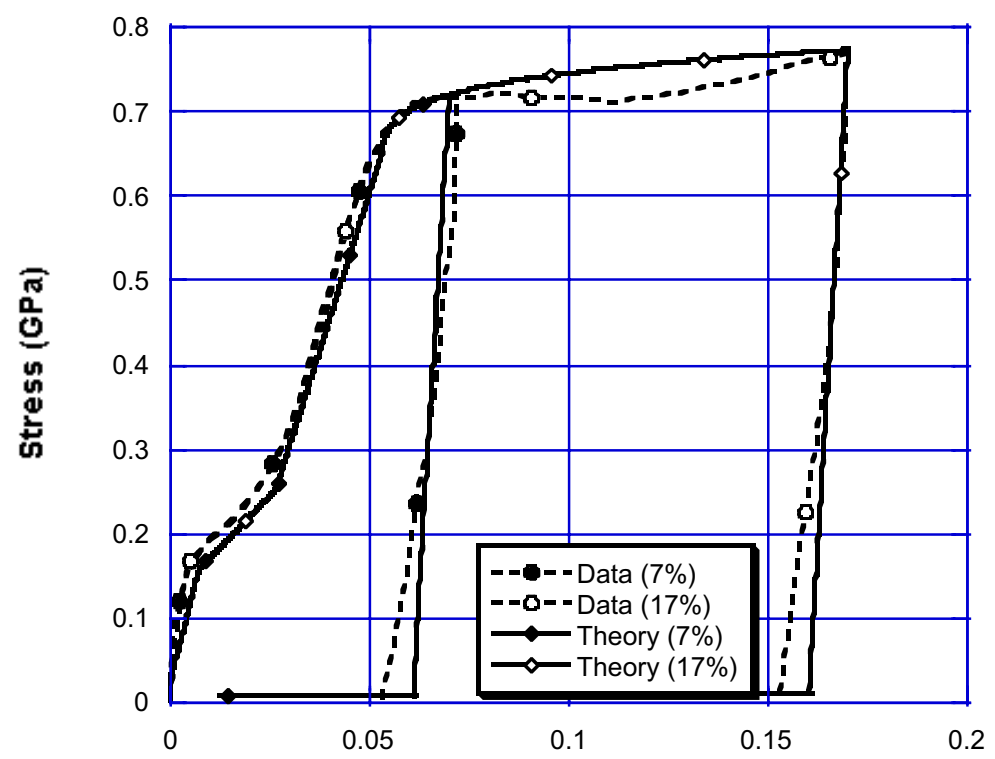

Strain

(a) stress versus strain

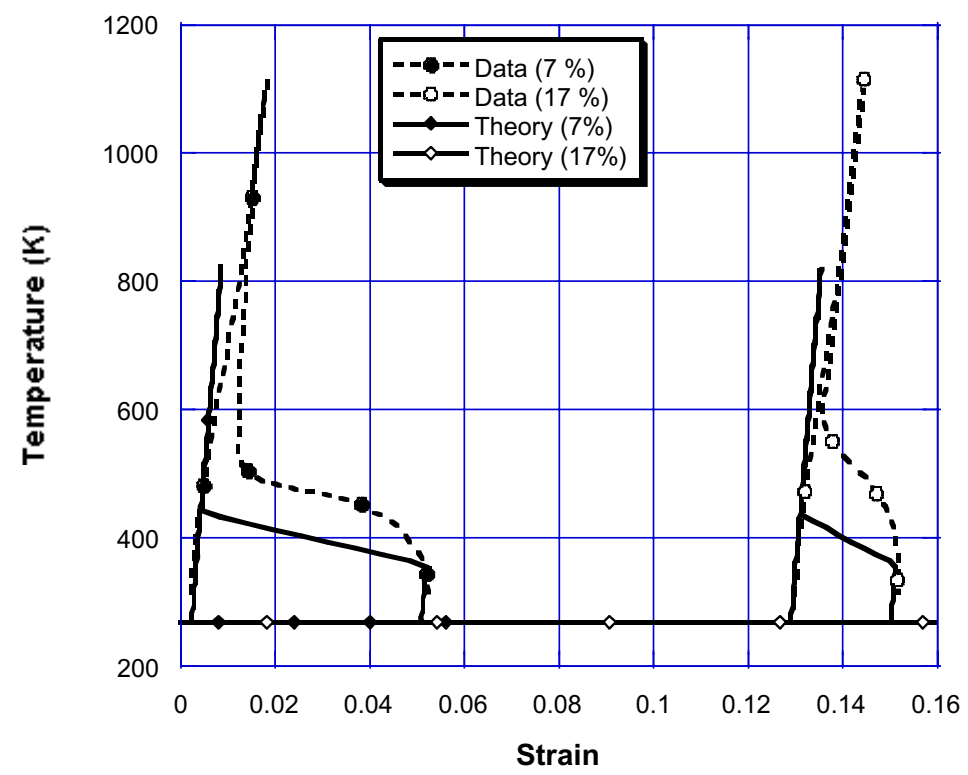

(b) Temperature versus strain

Figure 6. Comparison of simulations and data [3] for stress and temperature paths versus strain for U-6Nb. 
A comparison of the model and data [1-4] is provided in Figs. $6 \mathrm{a}+\mathrm{b}$. A linear equation of state is used in the simulations. The recovery strain $\left(\mathrm{h}_{0}\right)$ was decreased linearly with maximum applied strain in the simulations. Also, $\mathrm{h}_{0}$ was degraded linearly during heating from its initial value at the martensitic finish temperaure $\left(\mathrm{M}_{\mathrm{f}}\right)$ to zero at the martensitic start temperature $\left(\mathrm{M}_{\mathrm{s}}\right)$. It may be seen from Fig. 6a that the theory models the mechanical features of the experiments well. That is, an elastic deformation is obtained for small stress ( $\tau<0.042 \mathrm{GPa}$ ). Between $0.042 \mathrm{GPa}$ and $0.64 \mathrm{GPa}$, the simulated stress-versus-strain path is a result of crystal reorientation. Above 0.64 $\mathrm{GPa}$, the model enters the regime of slip plasticity. Unlike the experimental data, the model predicts a linearly elastic unloading path. Following the loading-unloading path, a heatingcooling path between room temperature and approximately $800 \mathrm{~K}$ was considered. Heating the strained state between room temperature and the martensitic finish temperature results in a thermal-elastic response. Between the martensitic finish $\left(\mathrm{M}_{\mathrm{f}}=340 \mathrm{~K}\right)$ and start $\left(\mathrm{M}_{\mathrm{s}}=430 \mathrm{~K}\right)$ temperatures, the transformation from $\alpha^{\prime \prime}$ to $\gamma^{0}$ occurs and the strain decreases with increasing temperature. In the simulation, a thermoelastic response is obtained on further heating followed by cooling. It may be seen from Fig. $6 \mathrm{~b}$ that the theory models the thermal response qualitatively. The difference between the experiment and the simulation is due partly to excluding the $\gamma^{0}$ to $\gamma$ phase transformation in the model. Also, better transformation potential $\left(\phi^{t}\right)$ and kinetics $(\dot{\xi})$ will improve the comparison between theory and experiment. The thermoelastic cooling path is a result of heating above the martensitic start temperature where the recovery strain has degraded to zero.

The model was compared to data for uniaxial stress and uniaxial strain experiments for the baseline material in Figs. 7 and 8. A comparison of model with uniaxial stress experiments is provided in Fig. 7. A linear equation-of-state was used to generate the simulations in Fig. 7. It may be observed that the model compares well to both the low-strain-rate $\left(0.1 \mathrm{~s}^{-1}\right)$ and highstrain-rate $\left(2000 \mathrm{~s}^{-1}\right)$ data for U-6Nb (Fig. 7a). The elastic and reorientation (twinning) regimes are accurately modeled. The uniaxial stress simulations result in a smaller hardening response for plastic deformation, especially for the low-strain-rate simulation. This is a result of the smaller strain and strain-rate hardening as well as larger thermal softening for the simulations. The comparison between the simulations and experiment in the plastic regime can be improved by replacing the existing phenomenological flow stress $\left(Y_{s}^{p}\right)$ model [38] with a physically based model [47]. This will be pursued in the future. Properties for the austenitic $\left(\gamma^{0}\right)$ phase were obtained by recognizing that $\mathrm{U}-8 \mathrm{Nb}$ is in the $\gamma^{0}$ phase at room temperature (Fig. 1). Setting the initial volume fraction $(\xi)$ to zero, the uniaxial stress simulation is compared to U-8Nb data in Fig. 7b. Because room temperature was assumed for the initial state, the model predicts a reorientation response to the deformation during loading. Again, a good comparison is obtained between the simulation and experimental data. 


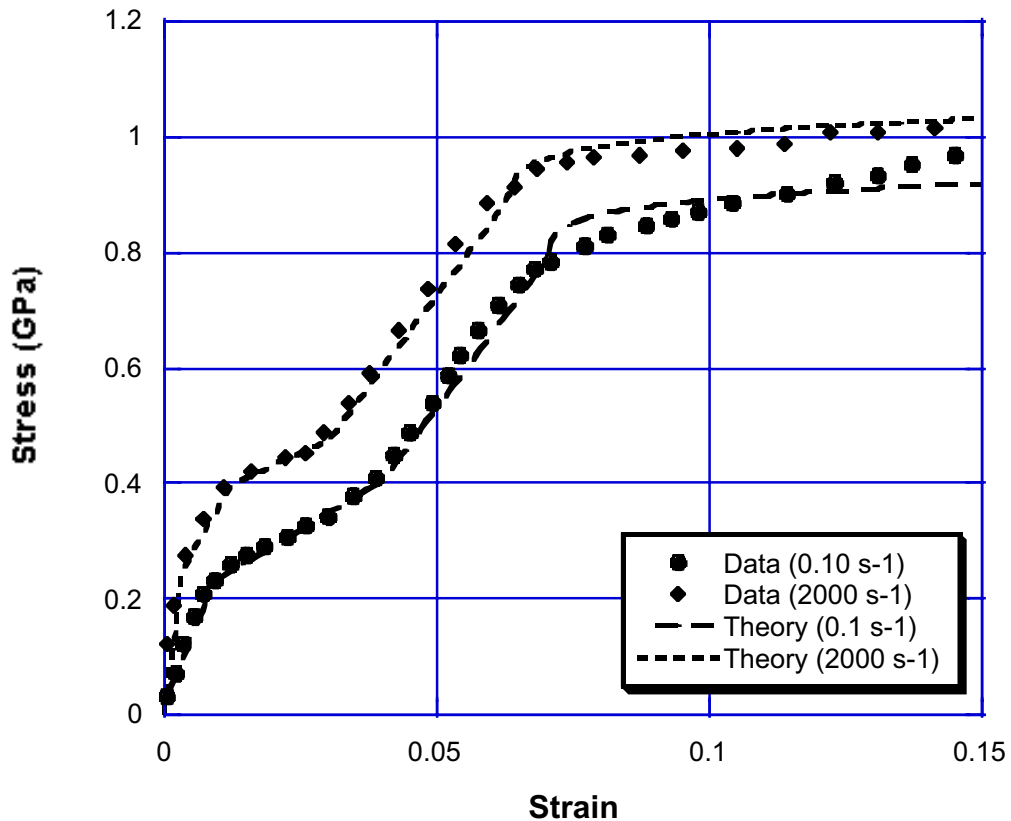

(a) $\mathrm{U}-6 \mathrm{Nb}$

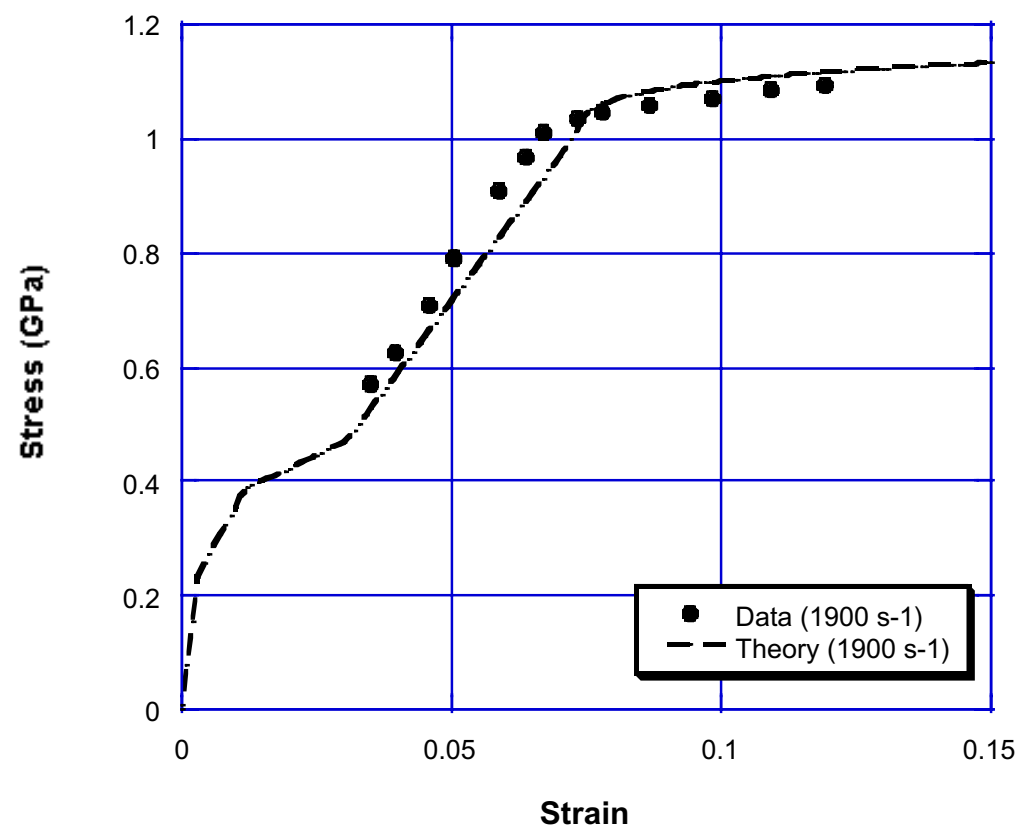

(b) $U-8 \mathrm{Nb}$

Figure 7. Comparison of simulations and data for uniaxial stress experiments [5]. 


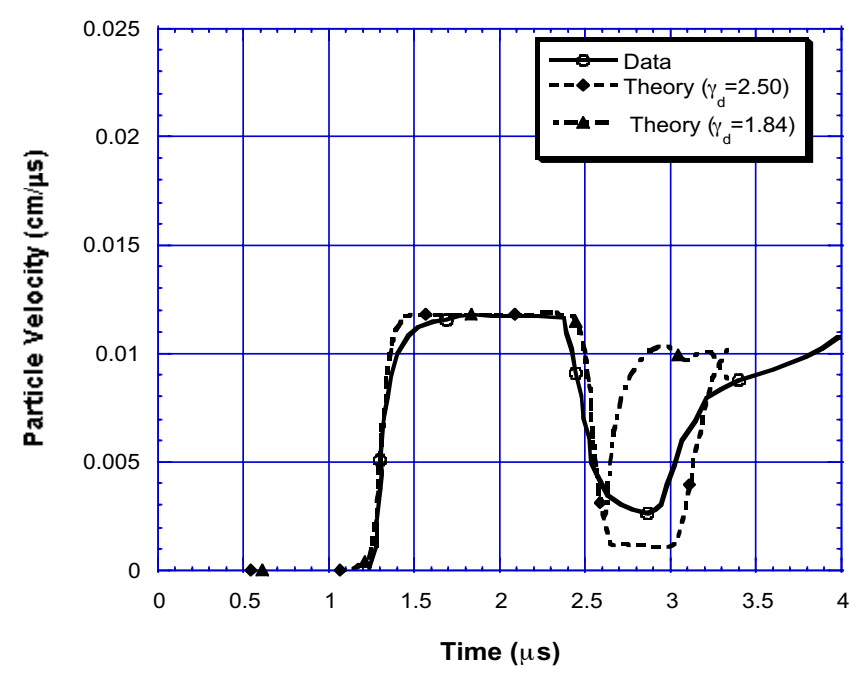

(a) Impact stress of 28.4 kbar.

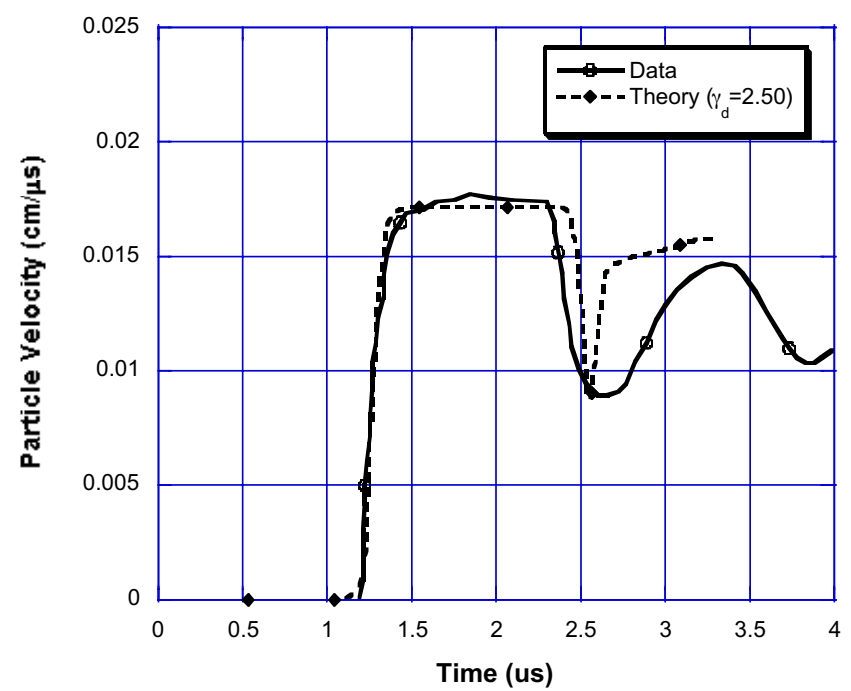

(b) Impact stress of $42.5 \mathrm{kbar}$.

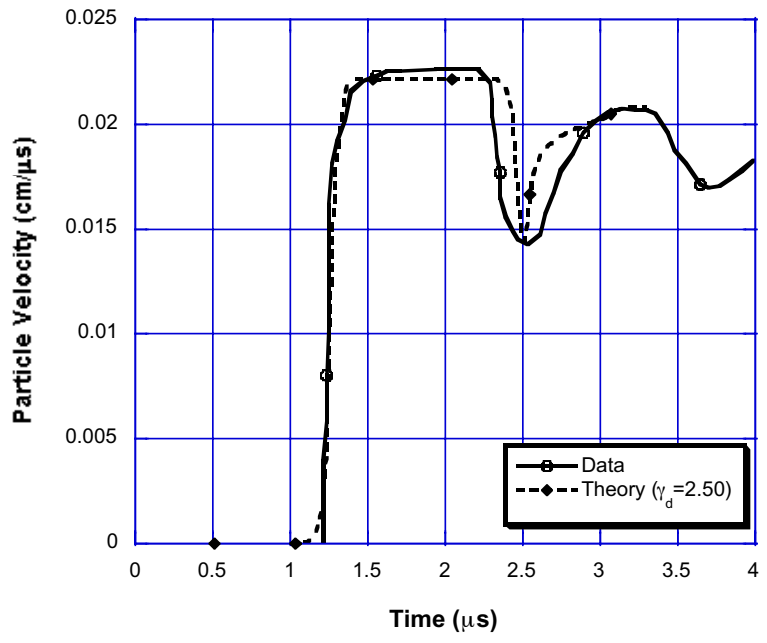

(c) Impact stress of $55.0 \mathrm{kbar}$.

Figure 8. Comparison of simulations and data for plate impact experiments [49]. 
A comparison of the uniaxial strain analysis and data $[48,49]$ is provided in Fig. 8 for three (3) plate impact experiments. A nonlinear equation of state was used for the plate impact simulations. The initial velocity of the flyer plate $\left(\mathrm{V}_{\mathrm{f}}\right)$ and the dimensions of the flyer $\left(\mathrm{x}_{\mathrm{f}}\right)$ and target $\left(\mathrm{x}_{\mathrm{t}}\right)$ plates are provided in Table III. A schematic diagram of the plate impact experiments is shown in Fig. 9. The particle velocity at the back of the U-6Nb target plate was measured in each of the experiments. For all three experiments, the flyer plate was made of z-cut quartz. Material parameters for the U-6Nb and z-cut quartz [50-53] used in the plate impact simulations are provided in Table I. The Hugoniot elastic limit (HEL) is not observed in either the simulations or the data for all three cases. The absence of an HEL may be a result of the crystal reorientation process that is present during compressive loading. The comparisons between the simulations and data for the plate impact experiments are good. An improvement of the simulation at the peak particle velocity $(\mathrm{t} \sim 1.5 \mu \mathrm{s})$ can be obtained by employing a physically based, rate-dependent model for the flow stress $\left(Y_{s}^{p}\right)$. The simulations did not closely match the data for the "pull-back" region of the plate experiments $(2.5 \mu \mathrm{s}<\mathrm{t}<2.7 \mu \mathrm{s})$. This was expected, however, because a rate-independent failure model was employed in the analysis. Consequently, a larger amount of porosity was calculated than observed in the post-mortem specimens. Also, the rate-independent model results in a sharper failure response (i.e., a shorter failure response time) than the experiment. A rate-dependent failure model [54], which will be implemented in

Table III. Plate impact experiments

\begin{tabular}{|l|l|l|l|l|}
\hline Material & $\begin{array}{l}\text { Impact Stress } \\
(\mathrm{kbar})\end{array}$ & $\begin{array}{l}\text { Flyer Velocity } \\
\left(\mathrm{V}_{\mathrm{f}}, \mathrm{km} / \mathrm{s}\right)\end{array}$ & $\begin{array}{l}\text { Flyer Thickness } \\
\left(\mathrm{x}_{\mathrm{f}}, \mathrm{mm}\right)\end{array}$ & $\begin{array}{c}\text { Target Thickness } \\
\left(\mathrm{x}_{\mathrm{t}}, \mathrm{mm}\right)\end{array}$ \\
\hline $\mathrm{U}-6 \mathrm{Nb}$ & 28.4 & 0.223 & 4.075 & 2.55 \\
\hline $\mathrm{U}-6 \mathrm{Nb}$ & 42.5 & 0.328 & 4.081 & 2.52 \\
\hline $\mathrm{U}-6 \mathrm{Nb}$ & 55.0 & 0.419 & 4.078 & 2.53 \\
\hline
\end{tabular}

Flyer Plate

(Quartz)

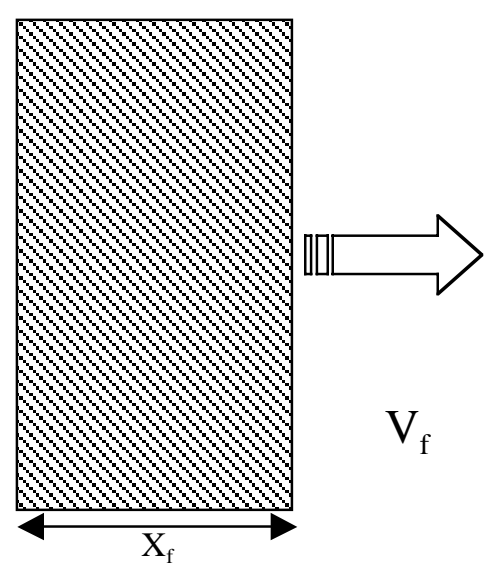

Target Plate

(U-6Nb)

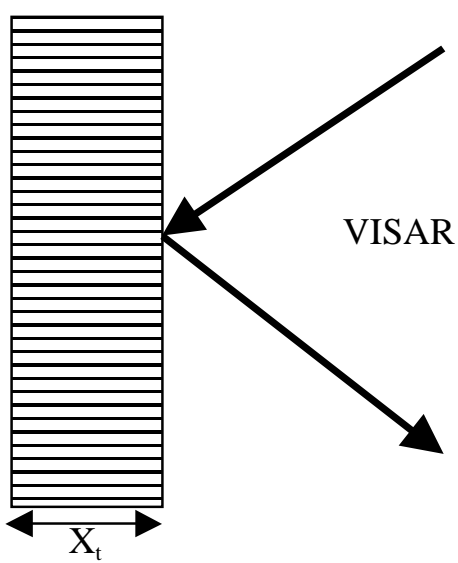

Figure 9. Schematic diagram of the plate impact experiments [49]. 
the future, will improve the simulations in the region of material failure. Better agreement between theory and data also can be achieved by including a void nucleation model. In Fig. 8a, simulations for two values of the exponential coefficient $\left(\gamma_{d}\right)$ for the strain to failure are provided. The larger value $\left(\gamma_{d}=2.50\right)$, which was the base-line value, results in no material failure for the simulation. The smaller value $\left(\gamma_{d}=1.84\right)$ results in material failure and the ensuing "pull-back" response of the particle velocity. The experimental data lie between these two simulations. With the exception of carbides, which were crushed during the initial compression, no damage was observed in the post-mortem specimen for the $28.4 \mathrm{kbar}$ experiment (Fig. 8a). Comparisons between the model predictions and data for the base-line value of $\gamma_{d}=2.5$ are provided in Figs. $8 \mathrm{~b}$ and $8 \mathrm{c}$ for impact stresses of $42.5 \mathrm{kbar}$ and $55.0 \mathrm{kbar}$, respectively.

\section{Summary}

A framework for the development of a three-dimensional constitutive model that includes crystal reorientation, phase transformation, plasticity, and failure for the conditions of high strain rate has been provided. This framework was used to develop a phenomenological model that also includes nonlinear elasticity (equation of state), rate-dependent plasticity, and porosity growth. A phase diagram in stress-versus-temperature space was used to guide the solution procedure for the material state. An implicit numerical algorithm was developed to obtain a solution to the system of equations for the material model. Consequently, the model imposes no additional timestep constraints on a structural analysis that utilizes the theory. The model was compared to experimental data for uranium-niobium alloys. The numerical simulations demonstrate the ability of the model to capture the effects of crystal reorientation, phase transformation, ratedependent plasticity, and failure. Material parameters were chosen for two pedigrees of material. It was observed that loading-unloading as well as heating-cooling simulations resulted in the observed material responses. Simulations of the model for constant temperature uniaxial stress and uniaxial strain (plate impact) experiments provided good agreement with data. Simulations with heating and cooling experiments, however, provided only qualitative agreement. This poorer agreement was due, in part, to the absence of the high-temperature transformation $\left(\gamma-\gamma^{0}\right)$ and the high-temperature phase $(\gamma)$. These features were omitted because of the lack of information related to both the transformation and properties of the high-temperature phase $(\gamma)$. Better transformation potential $\left(\phi^{t}\right)$ and kinetics $(\dot{\xi})$ also will improve agreement between theory and experiments. It also was demonstrated that improved models for rate-dependent plasticity and ductile failure would result in better agreement with experimental data. Further improvements to the failure model include the addition of a void-nucleation and a voidcoalescence model. Improvements to the material model include a physically based, ratedependent, flow-stress model and a rate-dependent porosity growth model. Also, improved models for the degradation of the recovery strain $\left(\mathrm{h}_{0}\right)$ with plastic strain and temperature will be considered. Future consideration will be given to kinematic hardening and the nonassociative behavior of the inelastic strains related to crystal reorientation and phase transformation. Better descriptions for these inelastic strains will provide an improved material response for multiple loading and unloading deformation paths. These additions will be made as the necessary data become available. 


\section{Acknowledgements}

The authors are indebted to a number of individuals for providing input to this effort. E.C. Flower-Maudlin and P.J. Maudlin are acknowledged for providing programmatic support. Discussions with G.T. Gray, R.D. Field, D.J. Thoma, D. Brown, and M. Bourke related to the metallurgy of uranium-niobium alloys were invaluable. Also, the technical interactions with P.J. Maudlin, J.N. Johnson, and H.L. Schreyer are appreciated. Gratitude also is expressed to Deborah Burton, who reviewed the manuscript. This research was support by the joint Department of Energy (DOE) and Department of Defense (DoD) Munitions Technology Development Program, and the DOE Accelerated Strategic Computing Initiative (ASCI).

\section{References}

1. R. A. Vandermeer, D. A. Carpenter, W. G. Northcutt, and J. C. Ogle, in Proceedings of International Conference of Solid-Solid Phase Transformations, Pittsburgh, PA, 1982.

2. R. A. Vandermeer, Acta Metall. 28, 383 (1980).

3. R. A. Vandermeer, J. C. Ogle, and W. G. Northcutt, Metall. Mat. Trans. 12A, 733 (1981).

4. $\quad$ R. A. Vandermeer, J. C. Ogle, and W. B. Snyder, Scripta Metall. 12, 243 (1978).

5. C. M. Cady, G. T. Gray III, S. S. Hecker, D. J. Thoma, D. R. Korzekwa, R. A. Patterson, P. S. Dunn, and J. F. Bingert, in Constitutive and Damage Modeling of Inelastic Deformation and Phase Transformation, Proceedings of Plasticity, '99, edited by A.S. Kahn (1999).

6. R. D. Field, D. J. Thoma, P. S. Dunn, D. W. Brown, C. M. Cady, Phil. Mag. A 81, 1691 (2001).

7. D. W. Brown, M. A. M. Bourke, P. S. Dunn, R. D. Field, M. G. Stout, and D. J. Thoma, Metall. Mat. Trans. 32A, 2219 (2001).

8. K. Kadau, T. C. Germann, P. S. Lomdahl, and B. L. Holian, Science 296, 1681 (2002).

9. A. Saxena, T. Lookman, and A. R. Bishop, LAUR-99-0336, "Modeling of Multiscale Functionality in Elastic Materials,” Los Alamos National Laboratory (1999).

10. M. Huang and L. C. Brinson, J. Mech. Phys. Solids 46, 1379 (1998).

11. X. J. Gao, M. S. Huang, and L. C. Brinson, Int. J. Plast. 16, 1345 (2000).

12. M. S. Huang, X. J. Gao, and L. C. Brinson, Int. J. Plast. 16, 1371 (2000).

13. M. Paley and J. Aboudi, Mech Mater. 14, 127 (1992).

14. A. Bekker and L. C. Brinson, Mechanics of Phase Transformations and Shape Memory Alloys, AMD-Vol. 189' PVP-Vol. 292 (ASME, New York, 1994), p. 195.

15. L. C. Brinson, J. Intell. Mat. Systems Struct. 4, 229 (1993).

16. S. Govindjee and E. P. Kasper, Comput. Methods Appl. Mech. Eng. 171, 309 (1999). 
17. S. Govindjee and E. P. Kasper, J. Intell. Mat. Systems Struct. 8, 815 (1997).

18. C. Liang and C. A. Rogers, J. Intell. Mater. Syst. Struct. 1, 207 (1990).

19. V. I. Levitas, Int. J. Solids Struct. 35, 889 (1998).

20. J. Lemaitre and J. L. Chaboche, Mechanics of Solid Materials (Cambridge University Press, New York, 1990).

21. G. A. Maugin, The Thermomechanics of Plasticity and Fracture (Cambridge University Press, New York, 1992).

22. J. Lubliner, Plasticity Theory (Macmillan Pub. Co., New York, 1990).

23. Y. C. Fung, Foundations of Solid Mechanics (Prentice-Hall Inc., Englewood Cliffs, NJ, 1965).

24. M. W. Lewis and H. L. Schreyer, in High-Pressure Shock Compression of Solids II, Dynamic Fracture and Fragmentation, edited by L. Davison, D. E. Grady, and M. Shahinpoor (Springer Verlag, New York, 1996).

25. C. Liang and C. A. Rogers, J. Engr. Math. 26, 429 (1992).

26. J. G. Boyd and D. C. Lagoudas, Int. J. Plast. 12 (6), 805 (1996).

27. V. Tvergaard and A. Needleman, Int. J. Fract. 37, 197 (1988).

28. A. L. Gurson, J. Eng. Mater. Technol. 99, 2 (1977).

29. J. N. Johnson and F. L. Addessio, J. Appl. Phys. 64, 6699 (1988).

30. J. B. Leblond, G. Mottet, J. Devaux, and J. C. Devaux, Mat. Sci. Tech. 1, 815 (1985).

31. J. B. Leblond, G. Mottet, and J. C. Devaux, J. Mech. Phys. Sols. 34, 395 (1986).

32. J. B. Leblond, G. Mottet, and J. C. Devaux, J. Mech. Phys. Sols. 34, 411 (1986).

33. A. S. Oddy, J. A. Goldak, and J. M. M. McDill, Eur. J. Mech., A/Solids 9, 253 (1990).

34. Y. B. Zel'dovich and Y. P. Raizer, Physics of Shock Waves and High-Temperature Hydrodynamic Phenomena, Vol. II (Academic Press, Inc., New York, 1967).

35. L. E. Malvern, Introduction to the Mechanics of a Continuous Medium (Prentice-Hall, Inc., Englewood Cliffs, NJ, 1969).

36. A. C. Eringen, Nonlinear Theory of Continuous Media (McGraw-Hill Book Company, Inc., New York, 1962).

37. D. P. Flanagan and L. M. Taylor, Comp. Methods. Appl. Mech. Engr. 62, 305 (1987).

38. G. R. Johnson and W. H. Cook, Eng. Fract. Mech. 21, 31 (1985).

39. J. C. Simo and T. J. R. Hughes, Computational Inelasticity (Springer, New York, 1997).

40. N. Aravas, Int. J. Num. Methods Engr. 24, 1395 (1987). 
41. G. R. Johnson and T. J. Holmquist, LA-11463-MS, "Test Data and Computational Strength and Fracture Model Constants for 23 Materials Subjected to Large Strains, High Strain Rates, and High Temperatures," Los Alamos National Laboratory, 1989.

42. R. L. Jackson, Rept. No. RFP-1613, The Dow Chemical Company Rocky Flats Division, Golden, CO, 1971.

43. K. H. Ecklemeyer, A. D. Romig, and L. J. Weirick, Metall. Trans. 15A, 1319 (1984).

44. R. J. Jackson and D. V. Miley, Trans. of ASME 61, 336 (1968).

45. D. R. Lowry, A. Wolfenden, and G. M. Ludtka, J. Appl. Mech. 57, 292 (1990).

46. R. J. Jackson, in The Physical Metallurgy of Uranium Alloys, edited by J. J. Burke (Brookhill, Chestnut Hill, MA, 1976), p. 611.

47. P. S. Follansbee and U. F. Kocks, Acta Metall. 30, 81 (1988).

48. D. L. Tonks, J. E.Vorthman, R. S. Hixson, A. Kelly, and A. K. Zurek, in Shock Compression of Condensed Matter-1999, edited by M. D. Furnish, L. C. Chhabildas, and R. S. Hixson (AIP, New York, 1999).

49. R. S. Hixson, J. E. Vorthman, A. K. Zurek, W. W. Anderson, and D. L. Tonks, in Shock Compression of Condensed Matter-1999, edited by M. D. Furnish, L. C. Chhabildas, and R. S. Hixson (AIP, New York, 1999).

50. J. Wackerle, J. Appl. Phys. 33, 922 (1962).

51. G. Simmons and H. Wang, Single Crystal Elastic Constants and Calculated Aggregate Properties: A Handbook (The MIT Press, Cambridge, MA, 1971).

52. S. C. Jones and Y. M. Gupta, J. Appl. Phys. 88, 5671 (2000).

53. W. M. Rohsenow and J. P. Hartnett, Handbook of Heat Transfer (McGraw-Hill, New York, 1973).

54. F. L. Addessio and J. N. Johnson, J. Appl. Phys. 73, 1640 (1993). 

This report has been reproduced directly from the best available copy. It is available electronically on the Web (http://www.doe.gov/bridge).

Copies are available for sale to U.S. Department of Energy employees and contractors from:

Office of Scientific and Technical Information P.O. Box 62

Oak Ridge, TN 37831

(865) 576-8401

Copies are available for sale to the public from: National Technical Information Service

U.S. Department of Commerce

5285 Port Royal Road

Springfield, VA 22616

(800) 553-6847 
